\title{
Emerging anti-cancer molecular mechanisms of aminobisphosphonates
}

\author{
Michele Caraglia ${ }^{1}$, Daniele Santini², Monica Marra', Bruno Vincenzi, \\ Giuseppe Tonini ${ }^{2}$ and Alfredo Budillon ${ }^{1}$
}

\author{
1Department of Experimental Oncology, Experimental Pharmacology Unit National Institute of Tumours 'Fondaz. G. Pascale', \\ Via Mariano Semmola, 80131 Naples, Italy \\ 2Department of Medical Oncology, University Campus Bio-Medico, 00100 Rome, Italy
}

(Requests for offprints should be addressed to M Caraglia; Email: michele.caraglia@fondazionepascale.it)

\begin{abstract}
Bone metastases are common in patients with many types of cancer, especially breast and prostate cancer - in which the incidence is approximately $70 \%$ among patients with advanced metastatic disease. Aminobisphosphonates (NBPs) have entered clinical practice in the treatment of bone metastases from several neoplasms, including breast and prostate adenocarcinoma, as a result of their anti-resorption properties. However, evidence has accumulated on the direct anti-tumour effects of NBPs. This review describes the metabolic pathways that are putative molecular targets of NBPs and that are involved in the prenylation processes of several intracellular small GTP-binding proteins (ras family related proteins). The latter regulate the intracellular survival and proliferative pathways of tumour cells and could be the intracellular molecular targets of the NBPs responsible for the direct anti-cancer effects, even if definitive conclusions cannot be drawn at present. Different mechanisms have been reported to account for the anti-neoplastic action of NBPs, including: the induction of apoptosis; cell cycle perturbations; and anti-invasive, anti-migration and anti-angiogenic effects. Moreover, this review describes the most important clinical studies that demonstrate the activity of NBPs in preventing skeletal-related events induced by bone metastases. The main pharmacokinetic pitfalls of NBPs are described, and methods of overcoming these pitfalls through the use of liposome vehicles are proposed. Finally, the principal pre-clinical studies on the interaction between NBPs and other biological agents are also described; these studies may enable reductions in the in vivo NBP concentrations required to achieve anti-tumour activity. To date, however, the real molecular targets of NBPs are not completely known and new technological platforms are required in order to detect them and to develop new anti-cancer strategies based on the use of NBPs.
\end{abstract}

Endocrine-Related Cancer (2006) 13 7-26

\section{Introduction}

Bone metastases are common in patients with many types of cancer (Coleman 1997, Coleman 2001, Ferlay et al. 2001, Zekri et al. 2001), especially breast and prostate cancer - in which the incidence is approximately $70 \%$ among patients with advanced metastatic disease (Coleman 1997, 2001). Because patients with breast or prostate cancer have a relatively long median survival time after diagnosis of bone metastases, the prevalence of bone metastases is high. These two cancer types probably account for more than $80 \%$ of cases of metastatic bone disease. In addition, approximately $40 \%$ of patients with advanced lung cancer develop bone metastases.

The high prevalence of bone metastases in patients with advanced metastatic disease contributes substantially to the burden of disease. Bone metastases are associated with considerable skeletal morbidity including severe bone pain that may require strong narcotics or palliative radiation therapy — pathological fracture, spinal cord or nerve root compression, and hypercalcaemia of malignancy (HCM), which can substantially reduce quality of life. Across all tumour types, patients with breast cancer have the highest incidence of skeletal complications (Berenson et al. 
1998, Lipton et al. 2000, Rosen et al. 2004b, Saad et al. 2004). After over 2 years of follow-up, nearly $70 \%$ of patients treated with placebo had more than one skeletal complication, and approximately $50 \%$ experienced a pathological fracture (Lipton et al. 2000). Patients with multiple myeloma, prostate cancer, lung cancer or other solid tumours are also at high risk for skeletal complications. The most common events in all tumour types are radiation to bone and pathological fracture. These complications result from excessive bone metabolism, principally bone resorption which characterizes malignant bone lesions and leads to severe bone pain. Therefore, there is a great need for therapies that effectively inhibit bone resorption, thereby reducing the risk of skeletal complications. Consequently, bisphosphonates (BPs) have become the standard treatment for malignant bone disease. BPs effectively inhibit bone resorption, have been shown to significantly reduce the incidence of skeletal complications and have analgesic effects on bone pain (Ross et al. 2003).

Traditional approaches for treating patients with bone metastases include standard anti-neoplastic therapies (chemotherapy or biological therapies), which may be administered in conjunction with additional supportive or palliative therapies. Severe bone pain is treated with radiotherapy and/or radionuclides, and many patients also receive systemic analgesic treatment with non-steroidal anti-inflammatory drugs or opioids. Radiotherapy is also used to stabilize bone lesions and may prevent impending fractures. Orthopaedic surgery is used to treat existing fractures or to prevent impending fractures or spinal cord compression. In addition to these strictly palliative interventions, BPs have emerged in recent years as a highly effective therapeutic option for the prevention of skeletal complications secondary to bone metastases. BPs bind preferentially to bone at sites of active bone metabolism, are released from the bone matrix during bone resorption and potently inhibit osteoclast activity and survival, thereby reducing osteoclastmediated bone resorption (Fleisch 2002). Newer nitrogen-containing bisphosphonates (NBPs) - such as zoledronic acid (ZOL), pamidronate (PAM) and ibandronate (IBA) - have a unique mechanism of action and greater clinical activity than first-generation BPs such as etidronate and clodronate (Green 2003). These newer agents are orders of magnitude more potent than the first-generation compounds. Consequently, they can inhibit bone resorption at micromolar concentrations.

BPs inhibit osteoclast activity at multiple levels; they prevent differentiation of macrophages into osteoclasts, block the activity of mature osteoclasts and induce osteoclast apoptosis (Rodan 1998, Rogers et al. 2000). The exact molecular mechanisms of action of BPs are only partially understood and appear to differ among different families of BPs (Fleisch 1998, Rodan 1998). Non-nitrogen-containing BPs (e.g. clodronate and etidronate) can be incorporated into non-hydrolyzable ATP analogues, which accumulate intracellularly and thereby suppress ATP-dependent enzymes (Rogers et al. 1996a). NBPs inhibit critical enzymes of the mevalonate pathway, in particular farnesyl diphosphate synthase, required for the synthesis of farnesyl diphosphate and geranylgeranyl diphosphate, and thereby suppress prenylation of small GTPases essential for many cellular functions (Luckman et al. 1998, van Beek et al. 1999b, Bergstrom et al. 2000, Dunford et al. 2001).

Clinical and experimental evidence indicates that NBPs suppress the progression of bone metastases, and recent observations suggest that this effect may be independent of the inhibition of bone resorption (Neville-Webbe et al. 2002, Green 2003). Tumour progression and metastasis formation are critically dependent on tumour angiogenesis (Carmeliet \& Jain 2000). Anti-angiogenic treatments suppress tumour progression in animal models, and many anti-angiogenic substances are currently being tested in clinical trials for their therapeutic efficacy against human cancer (Carmeliet 2003). Recent evidence indicates that zoledronate possesses anti-angiogenic activities as discussed below.

\section{Biochemical pathways as molecular targets of NBPs: the mevalonate pathway}

NBPs are potent inhibitors of the synthesis of both farnesyl and geranylgeranyl lipidic residues and therefore, of protein isoprenylation. The consequences of this inhibition are the disruption of important signal transduction pathways that regulate the proliferation, the invasive properties and the pro-angiogenic activity of human tumour cells. In fact, the addition of a lipidic residue to all the small GTP-binding proteins is essential for their correct location on the inner side of the plasma membrane and for their consequent activation by external signals. In fact, they must co-localize with their effectors that are all placed on the inner side of the plasma membrane, in which location are also found the substrates that are necessary to mediate the different functions of this class of molecules. Among documented farnesylated proteins are: H-, K- and N-Ras GDP/GTP-binding GTPases; 
the nuclear lamins; and the kinetechores centromereassociated protein (CENP)-E and -F. Geranylgeranylated proteins include: GTP/GDP-binding GTPases, RhoA, RhoC, Rac1, cdc-42, Rab and R-Ras (Reid et al. 2004). RhoB is found both farnesylated and geranylgeranylated in cells (Armstrong et al. 1995), whereas K-Ras becomes geranylgeranylated when farnesyltransferase (Ftase) activity is blocked (Lerner et al. 1997, Rowell et al. 1997, Whyte et al. 1997).

In human cells, isoprenoids are derived from the mevalonate pathway that starts from reaction catalyzed by the 3-hydroxy-3-methylglutaryl CoA (HMGCoA) reductase (the rate-limiting reaction in cholesterol biosynthesis) which catalyzes the conversion of HMGCoA to mevalonic acid. The pathway triggered by this reaction can lead to the synthesis of a key isoprenoid molecule: the farnesyl-pyrophosphate (FPP) whose formation is catalyzed by the farnesylpyrophosphate synthase (FPPS) (Soma et al. 1992). FPP can be: converted by a series of reactions into cholesterol; or transferred on target cellular proteins as FPP itself (reaction catalyzed by farnesyltransferase); or firstly converted into geranylgeranyl-pyrophosphate and then transferred on cellular proteins by type I or type II geranylgeranyltransferase.

\section{The isoprenylation process}

The joining of the 15-carbon farnesyl group $\left(\mathrm{C}_{15} \mathrm{H}_{25}\right)$ and the 20-carbon geranylgeranyl group $\left(\mathrm{C}_{20} \mathrm{H}_{33}\right)$ to protein-cysteines at or near their carboxy-termini is catalyzed by protein FTase and protein geranylgeranyltransferase-I and -II (GGTase-I and GGTaseII) (Zhang \& Casey 1996). The prenyltransferases are heterodimers consisting of $\alpha$ - and $\beta$-subunits with combined molecular masses ranging from 91 to $98 \mathrm{kDa}$. The $\alpha$-subunits of FTase and GGTase-I are the same, and the $\beta$-subunits differ. The $\beta$-subunits of the three enzymes are homologous to the $\alpha$-subunits and to each other. The isoprenoid groups become linked to polypeptidic cysteines through thioether $(\mathrm{C}-\mathrm{S}-\mathrm{C})$ bonds. Conversion of the protein-cysteine acceptor site to protein-serine in oncogenic H-Ras prevents prenylation and abolishes its malignant transforming ability (Lowy \& Willumsen 1993). FTase and GGTase-I catalyze the prenylation of substrates with a carboxy-terminal tetrapeptide sequence called a $\mathrm{CA}_{1} \mathrm{~A}_{2} \mathrm{X}$ box, where $\mathrm{C}$ refers to cysteine, $\mathrm{A}$ refers to an aliphatic residue and $\mathrm{X}$ typically refers to methionine, serine, alanine or glutamine for FTase or to leucine for GGTase-I. Following prenylation of physiological substrates, the terminal three residues $\left(\mathrm{A}_{1} \mathrm{~A}_{2} \mathrm{X}\right)$ are subsequently removed by a $\mathrm{CA}_{1} \mathrm{~A}_{2} \mathrm{X}$ endoprotease and the carboxyl group of the terminal cysteine is methyl esterified by a methyltransferase (Zhang \& Casey 1996). Protein GGTase-II, or Rab GGTase, catalyzes the geranylgeranylation of Rab proteins that terminate in $\mathrm{CC}$ or $\mathrm{CXC}$ sequences. Rab proteins ending with $\mathrm{CXC}$ residues are methyl esterified; those ending with $\mathrm{CC}$ are not. FTase and GGTase-I can catalyze the prenylation of tetrapeptides, polypeptides and proteins containing appropriate $\mathrm{CA}_{1} \mathrm{~A}_{2} \mathrm{X}$ box sequences. GGTase-II, in contrast, cannot catalyze the prenylation of these peptides; it uses a Rab-Rab escort protein heterodimer as substrate (Zhang \& Casey 1996). There are a few exceptions to the substrate-specificity rules for FTase and GGTase-I noted above. K-RasB, which has a classical FTase $\mathrm{CA}_{1} \mathrm{~A}_{2} \mathrm{X}$ box (CVIM), is a substrate for FTase. Following inhibition of cellular FTase, K-RasB becomes a substrate for geranylgeranylation by GGTase-I (Gibbs 2001, Yokayama $\&$ Gelb 2001). The latter reaction is made possible by an upstream polybasic sequence that alters GGTase-I substrate specificity. Furthermore, RhoB, which contains a GGTase-I $\mathrm{CA}_{1} \mathrm{~A}_{2} \mathrm{X}$ box $(\mathrm{CKVL})$, is found in both farnesylated and geranylgeranylated forms in cells. This is due to the ability of GGTase-I to both geranylgeranylate and farnesylate this substrate (Armstrong et al. 1995). It appears that upstream sequences (as yet uncharacterized) are responsible for this altered substrate specificity. Moreover, Cdc42, which contains a carboxyterminal CCIF sequence, undergoes geranylgeranylation. Ordinarily GGTase-I substrates contain leucine in the $\mathrm{X}$ position of the $\mathrm{CA}_{1} \mathrm{~A}_{2} \mathrm{X}$ box, but $\mathrm{Cdc} 42$ represents an exception to the leucine rule (Roskoski 2003). All three prenyltransferases require $\mathrm{Zn}^{2+}$, and FTase and GGTase-II require $\mathrm{Mg}^{2+}$ for activity (Huang et al. 1997, Hightower et al. 1998, Spence \& Casey 2001, Terry et al. 2001, Urano et al. 2001, Yokayama \& Gelb 2001). Both protein geranylgeranylation and farnesylation are followed by the cleavage of the terminal tripeptide $\mathrm{A}_{1} \mathrm{~A}_{2} \mathrm{X}$, catalyzed by a specific peptidase, and by the subsequent methylation of the terminal cysteine catalyzed by a methyltransferase. Finally, the protein is ready to be translocated on the cellular membranes to receive extra- or intracellular signals. After methylation, a palmitoylation on the - $\mathrm{SH}$ group of the penultimate cysteine residue can occur. This last reaction is reversible and occurs only for Ras proteins with a cysteine residue upstream of the CAAX motif (namely H-Ras, N-Ras and K-Ras4A), whereas the other CAAX-triggered events are irreversible (Clarke et al. 1988, Hancock et al. 1991, Zhang \& Casey 1996) (for a summary see Fig. 1). 


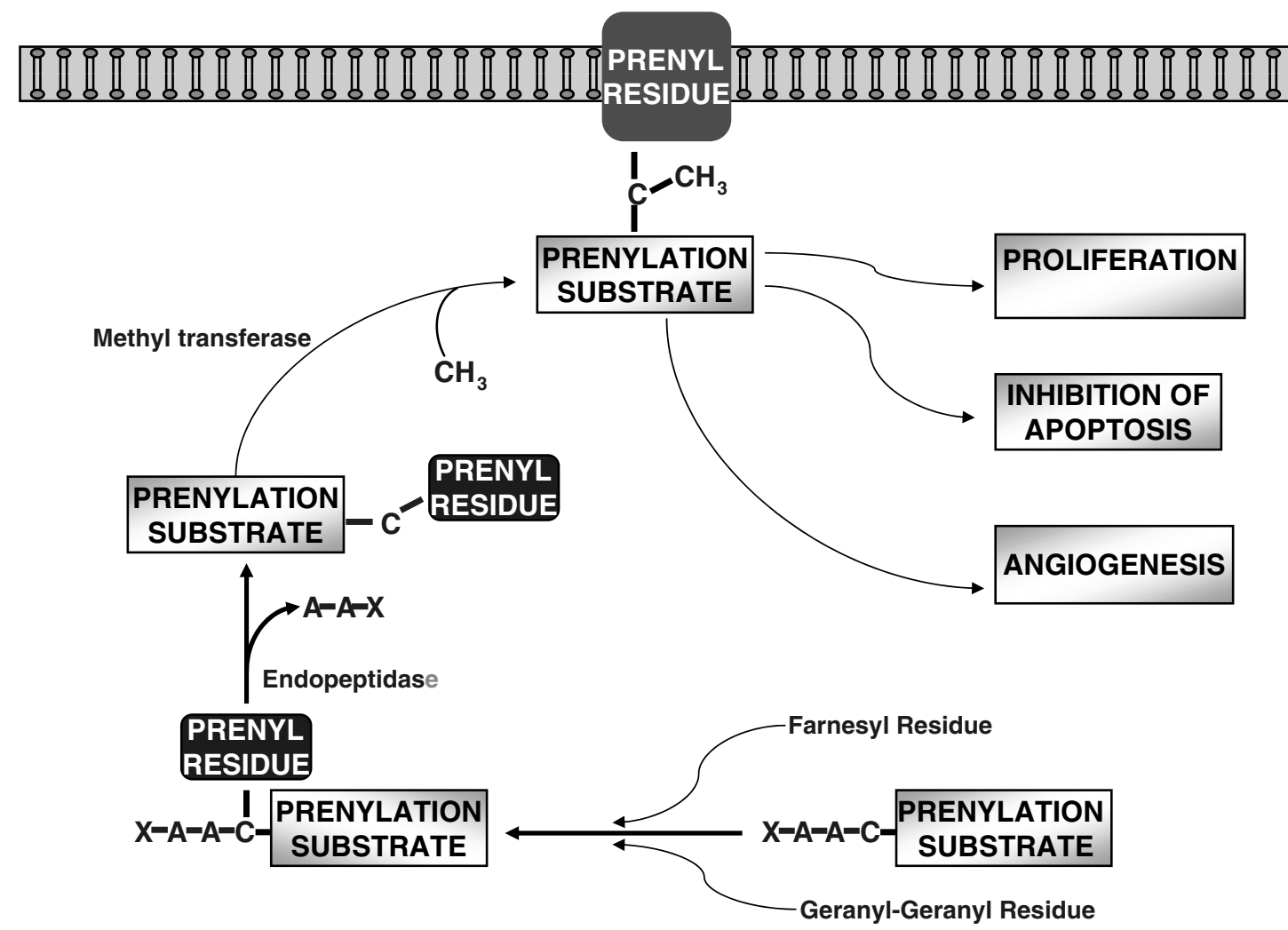

Figure 1 Isoprenylation mechanisms of intracellular substrates. The joining of the 15-carbon farnesyl group $\left(\mathrm{C}_{15} \mathrm{H}_{25}\right)$ and the 20-carbon geranylgeranyl group $\left(\mathrm{C}_{20} \mathrm{H}_{33}\right)$ to protein-cysteines at or near their carboxy-termini is catalyzed by protein FTase and protein GGTase-I or GGTase-II. FTase and GGTase-I catalyze the prenylation of substrates with a carboxy-terminal tetrapeptide sequence called a $C A_{1} A_{2} X$ box; where $C$ refers to cysteine, $A$ refers to an aliphatic residue and $X$ typically refers to methionine, serine, alanine or glutamine for FTase or to leucine for GGTase-I. Following prenylation of physiological substrates, the terminal three residues $\left(A_{1} A_{2} X\right)$ are subsequently removed by a $C A_{1} A_{2} X$ endoprotease and the carboxyl group of the terminal cysteine is methyl esterified by a methyltransferase. At this moment prenyl substrates are ready to be located on the inner side of the biological membranes to receive signals mediated by external factors.

\section{Suggested intracellular molecular targets of NBPs}

NBPs are currently used for the treatment of bone metastases and were initially thought to act by inhibition of formation of osteoclasts from immature precursor cells or by direct inhibition of resorption through induction of apoptosis in mature osteoclasts (Hughes et al. 1995). Recently, evidence suggests that NBPs including PAM and ZOL are also potent inducers of apoptosis in several cancer cell types such as myeloma (Shipman et al. 1997, Aparicio et al. 1998, Tassone et al. 2000) and breast (Senaratne et al. 2002), prostate (Lee et al. 2001) and pancreatic cancer (Tassone et al. 2003) as well as in macrophage (Rogers et al. 1996b) and intestinal epithelial cell lines (Twiss et al. 1999). These data indicate that the beneficial effect of NBPs on metastatic bone disease may result also from direct anti-cancer activity that may affect a broad range of tumours. The molecular basis of the NBP anti-cancer action relates to their ability to inhibit the farnesyl diphosphate synthase, probably by mimicking the diphosphate moiety (van Beek et al. 1999a). Therefore, they are also inhibitors of the synthesis of higher isoprenoids such as geranylgeranyl diphosphate. In contrast to farnesyltransferase inhibitors (FTIs) or geranylgeranyltransferase inhibitors (GGTI), it is now emerging that NBPs could inhibit both of the two different mechanisms of isoprenylation of intracellular proteins.

Many solid tumours cause hypercalcaemic bone destruction and the primary cause of this is often due to release of parathyroid hormone-related peptide (PTHrP). This may be released by the primary tumour, or by metatases, and can cause intense general or local bone destruction. Moreover, transforming growth 
factor (TGF)- $\beta$, one of the most abundant of the bonederived factors, promotes increased production of PTHrP by tumour cells, establishing a 'vicious cycle' leading to progressive tumour growth and bone destruction. BPs interrupt this cycle by inhibiting osteoclasts, in part by inducing osteoclast apoptosis (Mundy et al. 2001).

However, the exact molecular target of NBPs is still unknown and its identification could be useful in potentiating the beneficial effects of these drugs. Several isoprenylated molecules are emerging as potential targets of NBPs and they could be differently implicated in the biological effects induced by these agents. In order to be clear on the identification of the emerging molecular mechanisms responsible for the different biological effects (antiproliferative, antiinvasive and anti-angiogenic), each effect will be discussed separately.

\section{Anti-proliferative effect: apoptosis and cell cycle disruption}

Taking into account the relative importance of ras in regulating cell proliferation of several tumours both in vitro and in vivo, attention has been focused on ras in order to explain the direct anti-proliferative effects of NBPs. Two mechanisms of NBP-induced tumour growth inhibition have been described: cell cycle disruption and apoptosis. In this regard, it has recently been demonstrated in vitro that NBPs, such as PAM and ZOL, induce apoptosis and growth inhibition in human epidermoid cancer cells, together with depression of ras signalling and of Erk and Akt survival pathways. These effects occurred together with poly (ADP ribose) polymerase (PARP) fragmentation and the activation of caspase 3. Moreover, the latter seemed to be essential for apoptosis induced by NBPs in this experimental model. The synthesis of isoprenoids appeared largely responsible for the biological and biochemical effects of NBPs since the addition of farnesol $(\mathrm{FOH})$, which restores farnesylation, to tumour cells completely antagonized apoptosis and the inhibition of ras activity in tumour cells exposed to NBPs. These data suggest that the activity of NBPs could be due to the inactivation of the farnesylpyrophosphate synthase activity (Caraglia et al. 2004). Moreover, the effects of ZOL on growth inhibition and apoptosis seemed to be p53-independent (Kuroda et al. 2004). In fact, Kuroda et al. have demonstrated that $40 \mu \mathrm{M}$ ZOL induced about $40 \%$ apoptosis in leukaemia and colon cancer cells. The effect on growth inhibition was not dependent on p53 function since p53-defective colon cancer HCT116/E16 cells were equally as sensitive to ZOL as the parental cells. In these experimental conditions, ZOL decreased rap-1A prenylation and Erk activity, but had no effects on the expression of cyclin-dependent kinase inhibitors p27 and $\mathrm{p} 21$, and also increased the expression of M-phase cyclins. These results suggest that ZOL induced p53independent growth inhibition and apoptosis in these experimental systems. In contrast to the results of Caraglia et al. (2004) apoptosis induced by NBPs could also be due to the inhibition of ras geranylgeranylation instead of farnesylation as recently demonstrated by Senaratne et al. (2002). These conclusions are further supported by the findings of Coxon et al. (2004) who described apoptotic effects after $48 \mathrm{~h}$ of exposure to $100 \mu \mathrm{M}$ ZOL on prostate adenocarcinoma DU145 and PC3 cells. Apoptosis was completely antagonized by both the pan-caspase inhibitor and by the addition of geranyl-geranol $(\mathrm{GGOH})$, which restores geranylgeranylation, but not by FOH. Similar effects on apoptosis induction were also recorded after FTI manumycin A addition; this was, however, aspecific and also acted on GGTase. In this report, the inhibition of Rho A, a geranylgeranylated protein, through the use of $\mathrm{C} 3$ exoenzyme, was not able to induce apoptosis. Therefore, the authors failed to detect a putative molecular target of NBPs and it could only be suggested that a ras isoform or another GTPbinding protein that can be geranylgeranylated was involved. On the other hand, other data exclude the involvement of ras in the anti-proliferative effects exerted by ZOL on human prostate adenocarcinoma cells. In fact, Nogawa et al. (2005) found that the amount of membrane-anchored ras (the active fraction of ras) was clearly independent of ZOL-mediated growth inhibition of prostate cancer cell lines and concluded that geranylgeranylation of a still unknown substrate could be a therapeutic target in this experimental model. Moreover, it was also shown that PAM, alendronate and risedronate were all able to induce apoptosis in osteoclasts through the caspase cleavage of mammalian sterile 20-like kinase 1 (Mst1) to form the active $34 \mathrm{kDa}$ species associated with apoptosis. Moreover, these effects seemed to be independent on the blockade of geranylgeranylation (Reszka et al. 1999). Both incandronate and etidronate accelerate phosphate-primed mineralization of a murine calvariaderived osteoblastic cell line through the Erk1/2-Cbfa1 signalling pathway again in a ras-independent manner (Fujita et al. 2001). In this report, a differential involvement of Erk1/2 and Akt-dependent pathways was also described since risedronate suppressed the phosphorylation of ERK 1/2, affected the intracellular distribution of Bcl-xL and facilitated dephosphorylation 
of Bad at Ser112 (an ERK phosphorylation site), but not at Ser136 (an Akt phosphorylation site). All of these apoptosis-related changes induced by risedronate were strongly suppressed by cytochalasin B, an inhibitor of actin filament polymerization, thus excluding ras involvement but not suggesting an alternative substrate (Fujita et al. 2005). Moreover, differential biochemical effects within the different NBPs can not be excluded. In fact, it is known that the anti-resorptive effects of PAM are not completely inhibited by the addition of $\mathrm{GGOH}$ which, in turn, is able to antagonize completely the effects of alendronate (van Beek et al. 2003).

Based on the evidence that NBPs act as inhibitors of geranylgeranylation, a later-generation NBP NE10790 was developed with the specific ability to inhibit the activity of Rab GGTase but with no activity against either FTase or GGTase I (Coxon et al. 2001). NE10790 was able to inhibit bone resorption without affecting osteoclast number and causing the formation of intracellular vacuoles and protrusions of the basolateral membrane, thus affecting Rab-mediated intracellular trafficking (Coxon et al. 2001). Therefore, it is possible to design NBPs with selective activity against GTP-binding proteins different from ras and rho.

Another way to induce cell growth inhibition is cell cycle perturbation. In this regard, it was reported that ZOL at concentrations higher than $100 \mu \mathrm{M}$ induced $75 \%$ growth inhibition after 4 days of treatment on both androgen-dependent $\mathrm{LnCaP}$ and androgenindependent PC3 prostate cancer cell lines (Corey et al. 2003). In these experimental conditions G1 accumulation was found, even at only 2 days from the beginning of the treatment. The same authors reported the anti-cancer effects of ZOL on bone PC3 and LnCaP xenografts and the effect was paralleled by a significant reduction in serum prostate-specific antigen (PSA). The ability of ZOL to induce growth inhibition in cancer cells has also been studied in correlation with the reduced expression of metallo-proteinase (MMP)-2 and MMP-9 in PC3 cells, but not LnCaP cells. The effects of NBPs on cell cycle inhibitors was further confirmed by Reszka et al. (2001) who described the effects of alendronate and risedronate on normal human epidermal keratinocytes (NHEKs). Alendronate and risedronate induced growth inhibition without apoptosis and with S-phase accumulation in NHEKs. These effects were paralleled by $\mathrm{p} 21$ and p27 increased expression and consequent decreased phosphorylation of $\mathrm{Rb}$ likely due to the inhibition of geranylgeranylation.

In summary, these findings suggest again that the real targets of NBPs, responsible for growth inhibition, are still undiscovered and that their identification requires further investigations.

\section{Anti-invasive effects}

It has been reported that ZOL is also able to inhibit tumour cell invasiveness of breast and prostate cancer at $1 \mu \mathrm{M}$ concentrations; this makes it 150 -fold more potent than other NBPs such as risedronate and PAM, and very different from non-nitrogen BPs such as clodronate (Boissier et al. 2000). At these concentrations, ZOL does not induce apoptosis and inhibits the in vitro activity of several MMPs. The authors suggest that this inhibition was due not to a decreased synthesis of the enzymes, but to the steric interaction between the bone hook of NBPs and the active site of the proteins, since only at higher concentrations were NBPs able to reduce the secretion of these enzymes. However, Montague et al. (2004) have reported that ZOL and PAM reduce prostate cancer PC3 invasion on matrigel chambers (also at a concentration of $5 \mu \mathrm{M}$ $\mathrm{ZOL}$ ) and inhibit the binding of $\mathrm{PC} 3$ to the marrow stroma. Finally, ZOL was also able to inhibit PC3 colony formation on marrow stroma at the optimal concentration of $10 \mu \mathrm{M}$. All these effects were paralleled by the inhibition of MMP7 secretion and tissue inhibitor of matrix metalloproteinase (TIMP)-2 expression. In these experimental conditions, decreasing vascular endothelial growth factor (VEGF) and granulocyte monocyte colony stimulating factor expression was also recorded. Denoyelle et al. (2003), in agreement with previous studies (Fromigue et al. 2000, Hiraga et al. 2001, Jagdev et al. 2001), have also shown that ZOL inhibits breast cancer cell proliferation, but only at high concentrations $(4100 \mu \mathrm{M})$ that are certainly higher than those obtained in vivo. The effect of ZOL has also been studied on breast MDAMB-231 cell invasion. After an $18 \mathrm{~h}$ incubation time, ZOL, at low concentrations (from $100 \mathrm{~nm}$ ), conferred potent anti-invasive properties on MDA-MB-231 cells $(62 \%$ decrease at $1 \mu \mathrm{M})$. As $\mathrm{ZOL}$ did not induce apoptosis at these concentrations, the possibility that ZOL interfered with invasion by inducing cell death was excluded. This is also in agreement with the observations of Boissier et al. (2000). The same authors have shown that it does not involve proteases involved in tumour invasion by inducing the degradation of the extracellular matrix (ECM). Indeed, neither MMP secretion nor u-PA (urokinase-plasminogen activator) expression was modified at concentrations that inhibit cell invasion. Reduction of the secretion of both MMP-2 and MMP-9 (Boissier et al. 2000) and u-PA expression in MDA-MB-231 cells required much higher concentrations. In contrast, u-PA receptors expressed on the cell surface of MDA-MB-231 cells were dramatically reduced by ZOL at low 
concentrations. u-PA receptor is a ligand for vitronectin, which is a common protein in the mature bone microenvironment (Cooper et al. 2002). Consequently, the decrease of u-PA receptor by ZOL could contribute to the previously reported prevention of breast cancer cell attachment on to bone matrices (van der Pluijm et al. 1996, Boissier et al. 1997). In this study, it was demonstrated that $\mathrm{GGOH}$, which restores geranylgeranylation, but not $\mathrm{FOH}$, which restores farnesylation, reversed the effect of ZOL, suggesting that the inhibition of protein(s) geranylgeranylation rather than farnesylation seems to account for ZOL antiinvasive action. To test this hypothesis further, the effect of FTI-277 and GGTI-298 (which potently and selectively inhibit FTase and GGTase respectively), was compared with the action of ZOL on breast cancer cell invasiveness (Lerner et al. 1995, Vogt et al. 1996). The incubation of MDA-MB-231 cells with GGTI-298 mimicked the anti-invasive effect of ZOL, whereas FTI-277 did not. Thus, inhibition of protein geranylgeranylation seems to be important in explaining the anti-invasive action of ZOL. This effect was also mimicked by $\mathrm{C} 3$ exoenzyme, which is a specific inhibitor of RhoA, but not other Rho subfamily members, Rac and Cdc42 (Boquet 1999). Therefore, it was suggested that the inhibition of cell invasion by ZOL could be related to the inhibition of RhoA cell signalling. This was also supported by the observation that ZOL at low concentrations prevents the translocation of RhoA from cytoplasm to the cell membrane. In contrast to the effect of ZOL on cell invasion, the inhibition of cell proliferation seemed to be independent of RhoA inactivation because at the concentration for which RhoA, but not ras, was inhibited, cell proliferation and apoptosis were unaltered. Denoyelle et al. (2003) reported that ZOL also inhibited the chemotactic effect induced by the chemokine SDF-1 on MDA-MB-231 cells. This observation constitutes an important addition to the mechanistic understanding of how NBPs, given in the adjuvant setting, could prevent the development of bone metastases as shown by two clinical trials (Diel et al. 1998, Powles et al. 2002). Similar data were obtained with aledronate on the invasiveness and migration of both ovarian and prostate cancer cells (Sawada et al. 2002, Virtanen et al. 2002). Sawada et al. (2002) have also reported that alendronate inhibited lysophosphatidic acid-induced migration of human ovarian cancer cells by attenuating the activation of RhoA. These effects were again antagonized completely by GGOH and partially by FOH. On the other hand, Virtanen et al. (2002) have demonstrated that alendronate was able to decrease the migration and invasion of human prostate cancer cells and these effects were completely antagonized by both GGOH and $\mathrm{FOH}$. Possible explanations of the discrepancy of this study with all the other reports could be the following: (a) compensatory conversion of some $\mathrm{FOH}$ to geranylgeranyl by farnesyl; (b) since rho can be activated by ras, Ras-activation induced by $\mathrm{FOH}$ could still stimulate cell spreading and actin filament assembly through the activation of Rho.

Taken together these data prevent conclusive remarks on the molecular targets of NBPs being given. However, considering the results from the literature it can be suggested that inhibition of the isoprenylation of intracellular proteins could be the mechanism of action of NBPs. Moreover, ras seems to be involved in the induction of apoptosis while rho-A is involved in the regulation of cell invasion (for a summary see Fig. 2).

\section{Anti-angiogenic effects}

Both in vitro and in vivo studies have further demonstrated that NBPs have anti-angiogenic effects. In vitro assays with human umbilical vein endothelial cells (HUVECs) have shown that ZOL dosedependently inhibited the proliferation of HUVECs induced by fetal calf serum and basic fibroblast growth factor (bFGF), and these findings have been confirmed in vivo.

Systemic administration of ZOL to mice resulted in potent inhibition of angiogenesis induced by s.c. implants impregnated with bFGF, with a dose of $3 \mu \mathrm{g} / \mathrm{kg}$ producing a $50 \%$ efficacy $\left(\mathrm{ED}_{50}\right)$ (Wood et al. 2002). It has also been reported that ZOL can reduce bone-tumour-associated angiogenesis in the murine 5T2 myeloma model (Croucher et al. 2003).

In another series of experiments, ZOL, as well as IBA, risedronate and clodronate, inhibited the formation of capillary-like tubules by HUVECs in vitro. In vivo, $\mathrm{ZOL}$ and IBA, but not clodronate, decreased revascularization (as measured by vessel area) of the ventral prostate gland in castrated rats treated with testosterone (Fournier et al. 2002).

The inhibitory effect of NBPs on endothelial cell adhesion and migration appears to be mediated, at least in part, by modulation of integrins (e.g. $\alpha_{v} \beta_{3}$ and $\alpha_{v} \beta_{5}$ ) that are involved in angiogenesis (Bonjean et al. 2001, Bezzi et al. 2003). Interestingly, $\alpha_{v} \beta_{3}$ integrin is also required for osteoclasts to adhere tightly to the bone and form resorption lacunae during active bone resorption, and $\alpha_{v} \beta_{3}$ expression confers on tumour cells a greater propensity to metastasize to bone (Pécheur et al. 2002). In fact, a small molecule inhibitor 


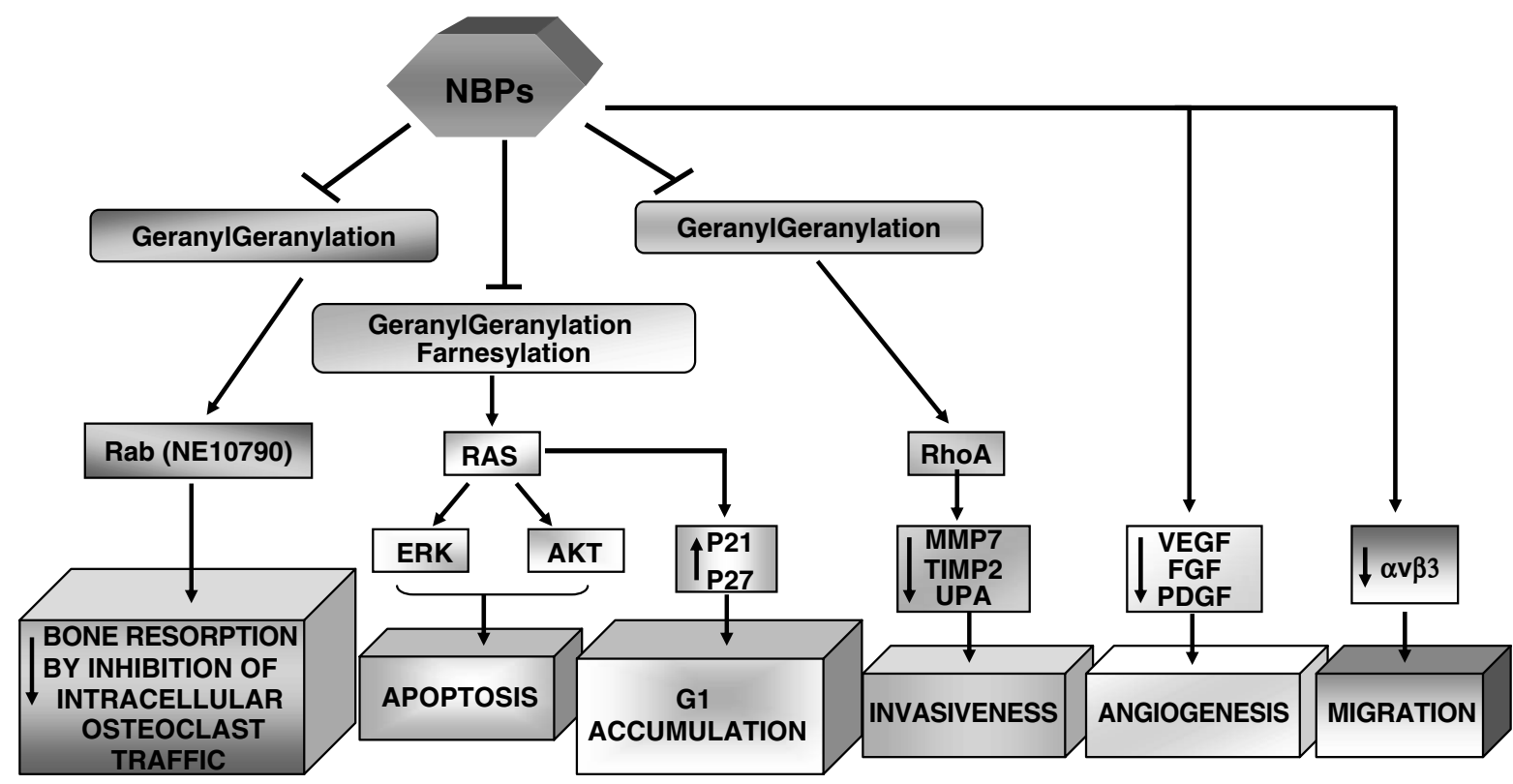

Figure 2 Intracellular molecular targets and modes of action of NBPs. NBPs can block the geranylgeranylation of Rab (reported for the new NBP NE10790), thus affecting bone resorption by inhibition of osteoclast intracellular traffic. NBPs can also antagonize geranylgeranylation and/or farnesylation of Ras family proteins (H-Ras, N-Ras, K-Ras) that, in turn, inhibit Erk and/or Akt activity or increase p21 and p27 expression. These effects can lead to apoptosis or G1 accumulation respectively, in osteoclasts and/or tumour cells. The block of geranylgeranylation of RhoA by NBPs can decrease the expression of molecules involved in invasion such as MMP7, TIMP-2 and u-PA. Finally, NBPs have been reported, in both in vitro and in vivo models (including humans), to reduce both the expression of angiogenic factors such as VEGF, bFGF and platelet-derived growth factor and to affect cell migration through the decrease of $\alpha_{v} \beta_{3}$ integrin expression.

of $\alpha_{v} \beta_{3}$ was recently shown to prevent effectively the metastasis of MDA-MB-435 breast cancer cells to bone (Harms \& Welch 2003).

Therefore, effects on $\alpha_{v} \beta_{3}$ could be pleiotropic on both bone resorption and tumour metastasis. In addition, it has recently been reported that ZOL decreases the survival of HUVECs by sensitizing them to tumour necrosis factor-induced programmed cell death. ZOL also appears to modulate serum levels of pro-angiogenic growth factors such as VEGF and bFGF in cancer patients (Santini et al. 2003), as previously demonstrated also for the parent compound PAM (Santini et al. 2002). These studies suggest a variety of potential mechanisms to account for the observed anti-angiogenic effects of NBPs (for a summary see Fig. 2).

\section{Clinical evidence of anti-resorptive and anti-cancer activity of NBPs}

Skeletal complications from bone metastases remain an important health care problem in patients with advanced cancer. However, BPs provide significant benefits to patients with bone metastases by decreasing skeletal complications and reducing bone pain. In patients with bone metastases from advanced breast cancer, several BPs - including oral clodronate, i.v. PAM, oral and i.v. IBA, and i.v. ZOL - have demonstrated significant clinical benefits over placebo. In this setting, i.v. PAM and ZOL have demonstrated the most consistent clinical benefits across multiple end points that provide both a conservative and comprehensive assessment of skeletal morbidity. ZOL has also been shown to be significantly more effective than PAM in patients with breast cancer. Consequently, i.v. ZOL is the standard of care in patients with breast cancer. In patients with prostate cancer, lung cancer, renal cancer and other solid tumours, the situation is quite different. In these tumour types, ZOL is the only BP that has demonstrated significant clinical benefit. Indeed, ZOL has demonstrated the broadest clinical activity of any BP across multiple tumour types.

Regardless of the cancer type, ZOL resulted in a statistically significant lower cumulative incidence of skeletal-related event (SREs) compared with PAM (in patients with breast cancer) and placebo (in patients with prostate cancer or other solid tumours). 
Moreover, the overall safety profile of ZOL was comparable with those of other i.v. BPs (Major et al. 2004).

The clinical benefits of BP therapy have been evaluated in many clinical trials designed to capture data on skeletal complications. The majority of these trials used a composite end point defined as a SRE or bone event, which generally includes events such as pathological fracture, radiation to bone, surgery to bone, spinal cord compression, and HCM. Such composite end points capture data on all clinically relevant events and are more likely to detect therapeutic benefits when treatment effects and disease morbidity are multifaceted (Johnson et al. 2003).

Using a composite definition of skeletal events, it is possible to assess treatment effect using a variety of outcome analyses. First-event descriptors such as proportion of patients with $\geq 1 \mathrm{SRE}$ or time to first SRE are objective and conservative end points that provide readily assessable estimations of treatment effect. Of these, the US Food and Drug Administration has suggested that time to first event is the preferred end point because it also accounts for the patient's time on the study (Williams et al. 2004).

However, first-event analyses only capture information about the first event and ignore data on all subsequent events that occur in any given patient. Skeletal morbidity rates (SMRs) or skeletal morbidity period rates (SMPRs) assess the number of events that occur during a designated time period (e.g. events per year). These analyses account for the occurrence of multiple skeletal events but assume that these events occur at a constant rate. However, clinical evidence suggests that patients with bone metastases exhibit considerable variation in both the number of skeletal events they experience and the rate at which these events occur (Major et al. 2004).

Moreover, skeletal events do not demonstrate random distribution but often occur in clusters. Therefore, analyses that assume a linear event rate tend to overestimate the differences between study groups and may unduly overestimate treatment effects (Major \& Cook 2002).

Regression analyses such as a Poisson analysis or the Andersen-Gill multiple event analysis are able to model all events, as well as the time between events, and are able to account for inter- and intra-patient variations in event rates (Andersen \& Gill 1982).

However, Poisson analyses that do not account for non-constant event rates are subject to the same limitations as those of other analyses, such as analyses using SMR, that do not account for variability in event rate. Therefore, multiple event analysis provides a statistically robust and comprehensive assessment of skeletal morbidity throughout the entire length of follow-up. Andersen-Gill multiple event analysis calculates a hazard ratio (HR) which indicates the extent to which the risk of skeletal events is affected by one specific treatment relative to another. A hazard ratio $<1$ indicates a favourable treatment effect. Recently, non-parametric methods for multiple event analysis have been described (Cook \& Lawless 1996, Ghosh \& Lin 2000).

These models calculate the cumulative incidence of skeletal complications and allow for right-censored data, thus accounting for death or study discontinuation for other reasons. Together, all these statistical analyses provide both conservative and comprehensive assessments of the clinical benefit of BPs in patients with bone metastases.

\section{NBPs in breast cancer}

ZOL ( $4 \mathrm{mg}$ in 15-min infusions every 4 weeks for 1 year) was also recently compared with placebo in 227 Japanese women with bone metastases from breast cancer (see Kohno et al. (2004) and Theriault et al. (1999)). In that trial, the primary end point was the SRE rate ratio adjusted for history of pathological fractures before study entry, which showed a significant $39 \%$ lower rate of SREs in the ZOL group (ratio $=0.61 ; P=0.027$ ). In addition, secondary efficacy analyses showed that ZOL produced a significantly lower percentage of patients with an SRE $(31 \%$ versus $52 \%$ for placebo; $P=0.001$ ) and significantly longer time to first SRE (median was not reached in ZOL group versus 360 days for placebo; $P=0.004$ ) than placebo. Multiple event analysis demonstrated a $44 \%$ lower risk of developing an SRE $(\mathrm{HR}=0.56$; $P=0.009)$ in the ZOL group. It is noteworthy that the magnitude of the clinical benefit of ZOL observed in that trial appears to be greater than that achieved with PAM or IBA in similar patient populations after 1 year of treatment (Hortobágyi et al. 1996, Theriault et al. 1999). Similar to the PAM trials, patients enrolled in this trial had predominantly osteolytic lesions. ZOL was well tolerated; the adverse events that occurred more often with ZOL than with placebo included acute-phase, infusion-related symptoms of pyrexia ( $55 \%$ versus $33 \%$ for placebo), fatigue ( $44.5 \%$ versus $31.9 \%$ for placebo) and arthralgia $(21.1 \%$ versus $15.9 \%$ for placebo). Only 1 of 114 patients experienced an elevated serum creatinine level with ZOL treatment in that study (Table 1).

Owing to the proven efficacy of PAM at the time, the pivotal trial of ZOL in patients with breast cancer 


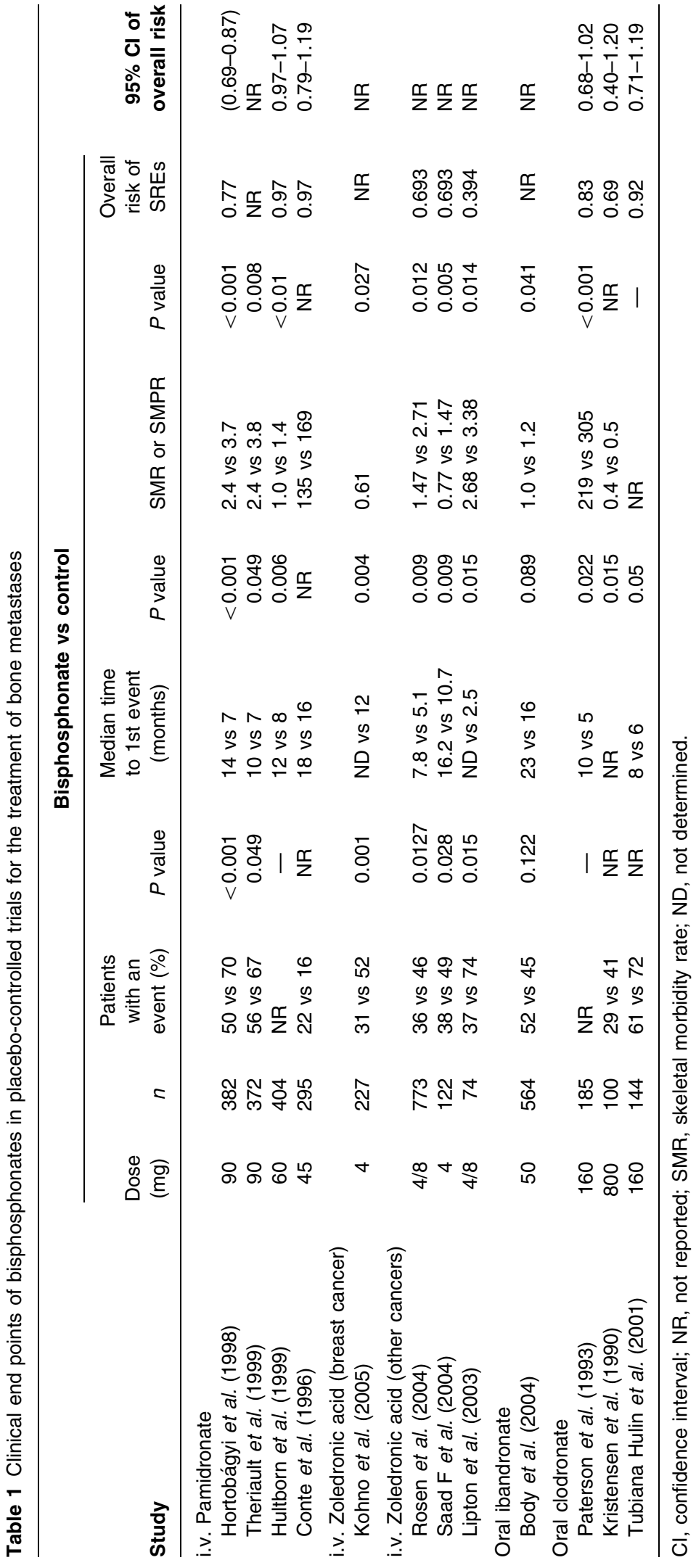

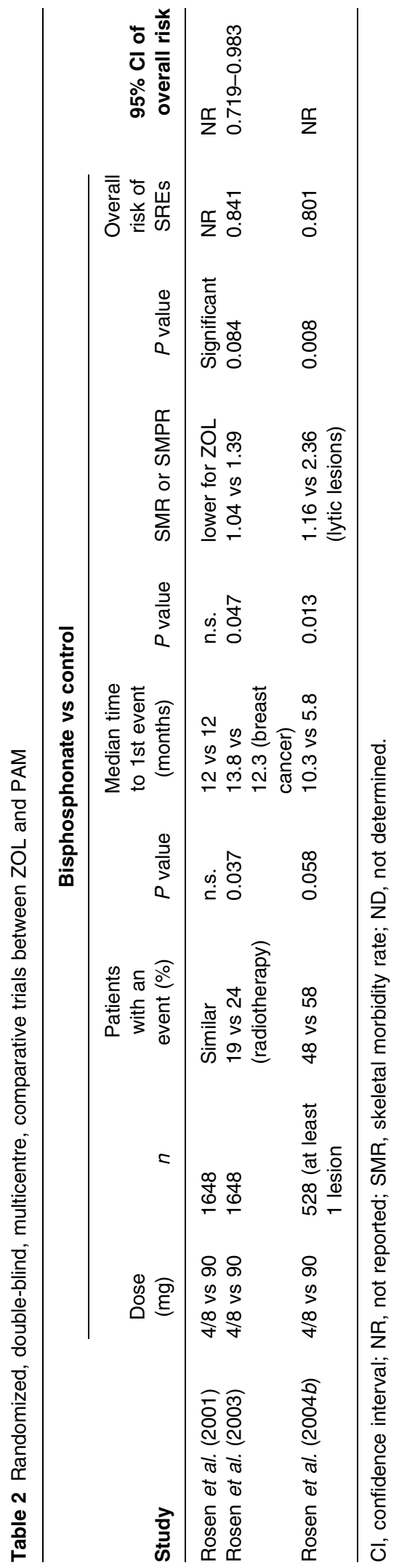


or multiple myeloma was designed as a non-inferiority trial comparing ZOL (4 mg via a 15-minute infusion) with PAM (90 mg via a 2-h infusion) (Rosen et al. 2003). In a stratified subset of patients with breast cancer, 377 patients were randomized to receive $4 \mathrm{mg}$ ZOL and 389 patients were randomized to receive $90 \mathrm{mg}$ PAM (every 3-4 weeks for 25 months). The primary end point (percentage of patients with $>1$ SRE) showed that ZOL was at least as effective as PAM (46\% versus $49 \%$ for PAM). Moreover, the prospectively planned Andersen-Gill multiple event analysis demonstrated that ZOL resulted in a $20 \%$ significantly lower risk of developing SREs than PAM (risk ratio $=0.799 ; P=0.025$ ). A similar, significantly lower cumulative incidence of SREs among patients treated with ZOL versus PAM was also demonstrated by the method of Cook \& Lawless (1996) $(P=0.046)$ (Major et al. 2003) (Table 2). In addition, among patients with predominantly osteolytic lesions, ZOL has been shown, by Andersen-Gill analysis, to result in a 30\% significantly lower risk of developing SREs compared with PAM $(P=0.010)$. Therefore, based on the comprehensive assessment of skeletal morbidity provided by two independent multiple event analyses, ZOL appears to be superior to PAM in patients with breast cancer. Based on this trial, ZOL has received broad international approval for the treatment of patients with bone metastases from breast cancer and is becoming the new standard of care worldwide (Rosen et al. 2004b).

\section{NBPs in prostate cancer}

In contrast to clodronate and PAM, ZOL (4 mg via a 15-min infusion every 3 weeks) has demonstrated statistically significant reductions in the incidence of SREs and sustained palliation of bone pain over 2 years in patients with bone metastases from hormoneresistant prostate cancer (HRPC). The results of this multicentre, randomized, placebo-controlled trial enrolling 643 patients were first reported at 15 months and then after 2 years of treatment (Zekri et al. 2001, Saad et al. 2004).

The primary end point was the percentage of patients with $>1$ SRE - defined as pathological fracture, radiation or surgery to bone, spinal cord compression, HCM, or change of therapy to treat bone pain. Secondary end points included time to first SRE, SMR, Andersen-Gill multiple event analysis, and Bone pain intensity (BPI) score. After 2 years, treatment with ZOL resulted in a significantly lower percentage of patients with $>1$ SRE $(38 \%$ versus $49 \%$ for placebo; $P=0.028$ ) and consistently lower incidences of all types of SREs, particularly fractures (Saad et al. 2003) (Table 1).

ZOL also produced a $36 \%$ significantly lower risk of developing a skeletal complication, as compared with placebo by multiple event analysis $(\mathrm{HR}=0.640$; $P=0.002)$ (Zekri et al. 2001) (Table 1).

Recently, Ernst and colleagues (2003) reported the results of a randomized, double-blind, controlled trial comparing the incidence of palliative response in HRPC treated with mitoxantrone and prednisone (MP) plus clodronate, with that of patients treated with MP plus placebo. They failed to demonstrate a significant difference between the arm groups but suggested a possible benefit of adding clodronate in patients with more severe pain.

\section{NBPs in other solid cancers}

To date, ZOL is the only BP to be evaluated for the prevention of skeletal complications in patients with bone metastases secondary to solid tumours other than breast or prostate cancer. In the first trial, 773 patients with bone metastases from non-small cell lung cancer (NSCLC) or other advanced-stage solid tumours were randomized to receive either $\mathrm{ZOL}$ ( $4 \mathrm{mg}$ via a $15-\mathrm{min}$ infusion) or placebo every 3 weeks for 21 months (Rosen et al. 2004a). That trial enrolled a diverse patient population composed of patients with NSCLC (49\% of patients) and more than 20 other tumour types including renal cell carcinoma (RCC), colorectal cancer, small cell lung cancer and bladder cancer. However, this was a poor-prognosis group of patients with a median survival of only 6 months, and patients received a median of only four infusions of ZOL. Nevertheless, Andersen-Gill multiple event analysis demonstrated that treatment with ZOL resulted in a $31 \%$ significantly lower risk of developing an SRE compared with placebo $(\mathrm{HR}=0.693 ; P=0.003)$, and ZOL produced a significantly longer median time to first SRE (236 days versus 155 days for placebo; $P=0.009$ ) (Table 1). A long-term subset analysis of 46 patients with RCC enrolled in that trial has also been reported (Lipton et al. 2004), showing that patients with bone metastases secondary to advanced RCC are at extremely high risk for skeletal complications. Among patients randomized to placebo, $79 \%$ had $>1$ SRE over 21 months of follow-up. Moreover, ZOL provided highly significant clinical benefits in this subset (Table 1). For example, patients treated with $4 \mathrm{mg}$ ZOL had a significantly lower SRE incidence of $41 \%(P=0.011)$ and longer time to onset of SREs (by approximately 1 year) than patients treated with placebo (median 424 days versus 72 days for placebo; 
$P=0.007)$. In addition, Andersen-Gill multiple event analysis showed that ZOL produced a $58 \%$ lower risk for SREs $(\mathrm{HR}=0.418 ; P=0.010)$. Even more noteworthy is the observation that treatment with $\mathrm{ZOL}$ resulted in greater bone lesion response and a significantly longer time to progression of bone lesions by approximately 6 months (median 256 days versus 89 days for placebo; $P=0.014$ ). $\mathrm{ZOL}$ was well tolerated in patients with RCC; the most common adverse events reported by patients for both $4 \mathrm{mg} \mathrm{ZOL}$ and placebo included bone pain, nausea, vomiting, anaemia and fatigue. There was no significant difference between treatment groups in the incidence of renal-related adverse events (Table 1). These results indicate that the predominantly osteolytic bone metastases associated with RCC are clinically aggressive, and these patients are at high risk for skeletal complications, but this risk can be significantly reduced with ZOL.

The clinical results based on the use of either clodronate or IBA are summarized in Table 1 and indicate that they are less promising than ZOL.

Most of the effects on bone are mediated by endocrine changes, either induction of an early menopause by chemotherapy and ovarian ablation, or further suppression of post-menopausal circulating oestrogens by aromatase inhibitors. Several studies have reported that cancer treatment-induced bone loss (CTIBL) can be prevented with BP treatment (Saarto et al. 1997, Powles et al. 1998). The Z-FAST study is the first trial designed to prevent, with ZOL, the bone loss that occurs with aromatase inhibitors in the typical post-menopausal setting. In this study, patients treated with adjuvant letrozole are randomized to either immediate treatment with ZOL (4 mg every 6 months) or to a delayed strategy. Preliminary 12-month bone mineral density (BMD) data have showed that upfront ZOL preserves bone density. However, further followup is required to determine the clinical importance of this over a wait-and-see policy (Brufsky et al. 2005).

\section{Predictive value of bone resorption and formation markers in bone metastatic cancer patients receiving the $B P$ ZOL}

Coleman et al. (2005) have recently investigated the correlation between bone metabolism and clinical outcome during BP therapy. They analysed urinary measurements of $\mathrm{N}$-telopeptide (Ntx) obtained in 1824 BP-treated patients (1462 multiple cancer types with ZOL and 362 with PAM) and estimated the correlation between this bone resorption marker and the relative risks for negative clinical outcomes. Interestingly, Ntx levels correlated with risk of skeletal complications and disease progression and, furthermore, high Ntx levels in each solid tumour category were associated with a 4- to 6-fold increased risk of death on study. This impressive study highlights the role of the bone resorption marker $\mathrm{Ntx}$ in providing correct prognostic information in patients with bone metastases receiving BPs. This could lead to the selection of cancer patients who might benefit most from therapy with BPs by evaluating urine or serum markers that predict who is at highest risk for skeletal complications and disease progression.

\section{Translation of the results derived from pre-clinical studies in the treatment of human neoplasms}

A series of pre-clinical findings suggest that NBPs have direct anti-tumour effects acting on different phases of tumour growth and progression. Moreover, the molecular targets and mechanisms of these effects are becoming clear. Clinical studies are confirming the activity of NBPs in preventing not only SREs but also skeletal metastases occurrence. The latter in vivo effect suggests a putative anti-invasive potential of NBPs. However, due to the intrinsic limitations of current NBPs, further efforts are required in order to allow the clinical translation of experimental results recorded to date and to increase the anti-cancer activity of these drugs. Two possibilities are the improvement of the pharmacokinetic profile and the design of rationalebased drug combinations.

\section{Improvement of the pharmacokinetic profile}

One of the most important limits of NBPs, which makes the direct anti-cancer activity difficult to demonstrate in vivo, is their pharmacokinetic profile. This issue is demonstrated by pharmacological studies performed on different NBPs. In fact, studies on ZOL pharmacokinetics demonstrate that, after intravenous administration (4 mg over $15 \mathrm{~min}$ ), an abrupt increase of its concentration in peripheral blood is recorded, as shown by estimations of the early distribution and elimination of the drug, which results in plasma halflives of the drug of about $15 \mathrm{~min}\left(t_{1 / 2 \alpha}\right)$ and of $105 \mathrm{~min}$ $\left(t_{1 / 2 \beta}\right)$ respectively. The maximum plasma concentration $\left(C_{\max }\right)$ of $\mathrm{ZOL}$ is about $1 \mu \mathrm{M}$; that is 10 - to 100 fold less than that required in in vitro studies to induce apoptosis and growth inhibition in tumour cell lines, while the concentrations required for anti-invasive effects are in the range of those achieved after in vivo administration. Moreover, approximately $55 \%$ of the initially administered dose of the drug is retained in the skeleton and is slowly released back into circulation, 
resulting in a terminal elimination half-life $\left(t_{1 / 2 \gamma}\right)$ of about 7 days (Chen et al. 2002, Skerjanec et al. 2003). Other studies performed on alendronate demonstrate that NBP concentration in non-calcified tissues declines rapidly at $1 \mathrm{~h}$ ( $5 \%$ of the initial concentration). On the other hand, its concentration in the bone continuously increases, reaching its peak at $1 \mathrm{~h}$, demonstrating that a significant redistribution of the drug from non-calcified tissues to bone occurs. The drug is retained in bone tissue for a long time and is slowly released into plasma, with a terminal half-life of about 200 days (Lin 1996). Similar data were obtained with IBA and ZOL (Chen et al. 2002, Barrett et al. 2004) demonstrating that long-lasting accumulation in bone is a common feature of NBPs. The rapid redistribution of NBPs results both in a short exposure of non-calcified tissues to the drug but also in a prolonged accumulation in bone where NBPs can also reach higher and tumoricidal concentrations. These considerations explain the relative efficacy of NBPs on tumours placed in bone tissues. A method of increasing the availability of these drugs in extra-bone tissues and increasing their plasma half-lives involves encapsulation in liposome vehicles (Harrington et al. 2002). Liposome-encapsulated clodronate, PAM and alendronate have already been produced and used for their ability to accumulate in the reticulo-endothelial system and for their macrophage-depleting properties (van Rooijen \& van Kesteren-Hendrikx 2002, Danenberg et al. 2003). However, these agents have non-specific uptake in white blood cells and are, therefore, not suitable for anti-cancer therapy. Stealth liposomes (pegylated liposomes or second-generation liposomes) are more germane for anti-tumour clinical practice because they evade interception by the immune system. They are characterized by very long circulation halflives, favourable pharmacokinetic behaviour and specific accumulation in tumour tissues (Cattel et al. 2004). One of the first anti-cancer drugs encapsulated in pegylated liposomes and used in clinical trials was doxorubicin (Gabizon et al. 2003). More recently, the ability of doxorubicin encapsulated in stealth liposomes to be active in the treatment of brain tumour metastases has also been reported (Caraglia et al. 2005). These favourable pharmacokinetic properties of pegylated liposomes could encourage their use as NBP vehicles in order to increase the uptake of the latter in tumour sites.

\section{Rationale-based combinations between NBPs and other biological agents}

On the basis of the emerging mechanisms of action of NBPs, several combinations of NBPs and other biological agents have been designed and their activity on tumour cell proliferation has been evaluated.

ZOL and other NBPs have been combined with different biological agents based on their ability to inhibit crucial processes of protein isoprenylation. In fact, the prenyltransferases are not strictly specific and a small $G$ protein can be the substrate for different enzymes. In fact, K-RasB, which has a classical FTase $\mathrm{CA}_{1} \mathrm{~A}_{2} \mathrm{X}$ box (CVIM), is a substrate for FTase, but following inhibition of cellular FTase, K-RasB becomes a substrate for geranylgeranylation by GGTase-I (Gibbs 2001). Similarly, RhoB, which contains a GGTase-I $\mathrm{CA}_{1} \mathrm{~A}_{2} \mathrm{X}$ box $(\mathrm{CKVL})$, is found in both farnesylated and geranylgeranylated forms in cells (Yokayama \& Gelb 2001). These events allow the alternative isoprenylation of the substrate of prenyltransferase inhibitors when FTIs are added to tumour cells. Based on the relevance of any farnesylation inhibitory effects on anti-tumour activity of the BPs, the FTI R115777 was used together with PAM or ZOL and the effects of the combination treatment on growth inhibition and apoptosis evaluated. BPs and FTI given in combination were strongly synergistic since a $\mathrm{CI}_{50}$ (the combination index of the two drugs calculated for $50 \%$ cell survival by isobologram analysis using dedicated software) of less than 0.5 was recorded (Caraglia et al. 2004). In fact, $\mathrm{CI}_{50}$ values less than 1.0 suggest synergism and values less than 0.5 suggest strong synergism in inducing growth inhibition by drug combinations (Chou \& Talalay 1984). Notably, low concentrations of FTI induced a strong increase of ras expression with only a moderate reduction of ras activity that was, on the other hand, significantly reduced by the combined treatment (Caraglia et al. 2004). These data suggest that escape mechanisms for the inhibition of isoprenylation of ras might be based on the geranylgeranylation or other prenylating processes (Lee et al. 2001). The addition of FOH to cells treated with the combination abolished the effects of the BPs/FTI combination on apoptosis and on the activity of the signalling molecules. These data suggest that the synergistic growth-inhibitory and pro-apoptotic effects produced by the NBP/FTI combination involve the inhibition of both Erk and Akt survival pathways acting in these cells in a ras-dependent fashion (Caraglia et al. 2004).

Andela et al. (2002) have recently reported that the NBP alendronate and R11577 used alone had no significant effects on the growth inhibition and apoptosis of murine lung alveolar carcinoma, but showed a reduction in in vitro invasiveness when the two drugs were combined. Moreover, alendronate 
potentiated the in vivo anti-metastatic effects of R115777.

Imatinib mesylate, a selective inhibitor of $\mathrm{Abl}$ tyrosine kinase, has significant and rapid activity against chronic myelogenous leukaemia (CML) and Philadelphia-positive $\left(\mathrm{Ph}^{+}\right)$acute lymphoblastic leukaemia (ALL). Targeting one of the Bcr-Abl downstream signaling proteins essential for Bcr-Ablmediated leukaemogenesis, in addition to Bcr-Abl, was intriguing. Several lines of evidence have implicated the Ras/mitogen-activated protein kinase (MAPK) signalling pathway as an important molecular target (Turhan et al. 1998, le Coutre et al. 2000, Mahon et al. 2000, Weisberg \& Griffin 2000, Druker et al. 2001a,b, Hofmann et al. 2002, Hoover et al. 2002, Ottman \& Hoelzer 2002, Yu et al. 2002). On the basis of these considerations Kuroda et al. (2004) have used imatinib in combination with $\mathrm{ZOL}$ in imatinibresponsive or -resistant AML cell lines. Interestingly, imatinib-resistant cell lines also displayed sensitivity to the growth inhibitory activity of both ZOL and PAM, and also ZOL induced a decrease of Rap-1A and ras prenylation, G2M-phase accumulation and apoptosis.

It was also reported that ZOL was able to induce growth inhibition of a small cell lung cancer (SCLC) cell line subcutaneously transplanted in nude mice and was synergetic on in vitro growth inhibition with several anti-cancer agents and had additive effects if combined with imatinib (Matsumoto et al. 2005). Another study examined the effects of combining a cyclooxygenase- 2 inhibitor SC236 with ZOL and/or docetaxel in a HER-2/neu-transfected and a control human breast cancer cell line. Enhanced growth inhibition was observed in both cell lines with both the combination of docetaxel and SC236, and of docetaxel and ZOL (Witters et al. 2003).

Zhang et al. (2004) have demonstrated a differential sensitivity of breast cancer cell lines to PAM based upon differential modulation of ras protein expression induced by the NBPs. They have found that MDA-175 was a PAM-resistant cell line in which the modulation of ras expression by PAM was lost. On the basis of these findings they have used in combination with PAM, imatinib or bortezomib, a proteasome inhibitor or rapamycin, an inhibitor of the mammalian target of rapamycin (m-TOR); all combinations showed additive effects in causing inhibition of proliferation in MDA-175 cells (Zhang et al. 2004). It was also reported that another newly synthesized NBP, minodronic acid, synergized with all-trans retinoic acid, thalidomide, or interferon beta on the growth inhibition and apoptosis of myeloma cells (Yata et al. 2002). More recently, it was shown that minodronic acid has anti-proliferative activity and reduces the prenylation of Rap-1A in human RCC cells (Yuasa et al. 2005).

The findings of synergy of interaction between NBPs and other agents could reduce the NBP concentrations required for anti-tumour activity and could allow the achievement of effective in vivo levels.

\section{Conclusions}

The discovery of the locus of action of NBPs could have important consequences in the understanding of their anti-cancer activity and may suggest pharmacological modifications that could be made to increase their tumouricidal activity. One example is given by liposomal formulations that could allow distribution to visceral cancer sites rather than NBPs being mainly accumulated in bone tissue.

The body of evidence accumulated on NBP mechanisms of action does suggest some innovative strategies based on the use of rationale-based drug combinations. The existence of a pro-apoptotic effect of NBPs based on the disruption of ras (or ras-like)-mediated pathways supports the combination between NBPs and other isoprenylation inhibitors such as FTIs. However, further pre-clinical investigations, eventually supported by advanced technological platforms, are required for the discovery of molecular targets of NBPs and for the optimization of their mode of administration.

\section{Acknowledgements}

We thank Dr S Addeo for his technical support and for useful discussion of the paper.

\section{Funding}

This work was partially supported by grants from both the Italian Ministry of Health (FSN2003 and FSN2004) and the Italian Association for Cancer Research (AIRC). The authors declare that there is no conflict of interest that would prejudice the impartiality of this scientific work.

\section{References}

Andela VB, Rosenblatt JD, Schwarz EM, Puzas EJ, O'Keefe RJ \& Rosier RN 2002 Synergism of aminobisphosphonates and farnesyl transferase inhibitors on tumor metastasis. Clinical Orthopaedics and Related Research 397 228-239.

Andersen PK \& Gill RD 1982 Cox's regression model for counting processes: a large sample study. Annals of Statistics 10 1100-1120. 
Aparicio A, Gardner A, Tu Y, Savage A, Berenson J \& Lichtenstein A 1998 In vitro cytoreductive effects on multiple myeloma cells induced by bisphosphonates. Leukemia 12 220-229.

Armstrong SA, Hannah VC, Goldstein JL \& Brown MS 1995 CAAX geranylgeranyl transferase transfers farnesyl as efficiently as geranylgeranyl to RhoB. Journal of Biological Chemistry 270 7864-7868.

Barrett J, Worth E, Bauss F \& Epstein S 2004 Ibandronate: a clinical pharmacological and pharmacokinetic update. Journal of Clinical Pharmacology 44 951-965.

Berenson JR, Lichtenstein A, Porter L, Dimopoulos MA, Bordoni R, George S, Lipton A, Keller A, Ballester O, Kovacs M et al. 1998 Long-term pamidronate treatment of advanced multiple myeloma patients reduces skeletal events. Journal of Clinical Oncology 16 593-602.

Bergstrom JD, Bostedor RG, Masarachia PJ, Reszka AA \& Rodan G 2000 Alendronate is a specific, nanomolar inhibitor of farnesyl diphosphate synthase. Archives of Biochemistry and Biophysics 373 231-241.

Bezzi M, Hasmim M, Bieler G, Dormond O \& Ruegg C 2003 Zoledronate sensitizes endothelial cells to tumor necrosis factor-induced programmed cell death. Evidence for the suppression of sustained activation of focal adhesion kinase and protein kinase B/Akt. Journal of Biological Chemistry 278 43603-43614.

Body JJ, Diel IJ, Lichinitzer M, Lazarev A, Pecherstorfer M, Bell R, Tripathy D \& Bergstrom B 2004 Oral ibandronate reduces the risk of skeletal complications in breast cancer patients with metastatic bone disease: results from two randomised, placebo-controlled phase III studies. British Journal of Cancer 90 1133-1137.

Boissier S, Magnetto S, Frappart L, Cuzin B, Ebetino FH, Delmas PD \& Clezardin P 1997 Bisphosphonates inhibit prostate and breast carcinoma cell adhesion to unmineralized and mineralized bone extracellular matrices. Cancer Research 57 3890-3894.

Boissier S, Ferreras M, Peyruchaud O, Magnetto S, Ebetino FH, Colombel M, Delmas P, Delaisse JM \& Clezardin P 2000 Bisphosphonates inhibit breast and prostate carcinoma cell invasion, an early event in the formation of bone metastases. Cancer Research 60 2949-2954.

Bonjean K, Bellahcene A \& Locigno R 2001 Zoledronate modulates endothelial cell surface receptors involved in angiogenesis. Proceedings of the American Association for Cancer Research 42106.

Boquet P 1999 Bacterial toxins inhibiting or activating small GTP-binding proteins. Annals of New York Academy Science 886 83-90.

Brufsky A, Harker WG, Beck JT, Carroll R, Tan-Chiu E, Seidler C, Lacerna L, Thomas E \& Perez E, The Z-FAST Study Group 2005 Zoledronic acid (ZA) effectively inhibits cancer treatment-induced bone loss (CTIBL) in postmenopausal women (PMW) with early breast cancer (BCa) receiving adjuvant Letrozole (Let): 12 mos BMD results of the Z-FAST trial. Journal of Clinical Oncology, 2005 ASCO Annual Meeting Proceedings, 23(16S) 533.
Caraglia M, D’Alessandro AM, Marra M, Giuberti G, Vitale G, Viscomi C, Colao A, Del Prete S, Tagliaferri P, Tassone P, Budillon A, Venuta S \& Abbruzzese A 2004 The farnesyl transferase inhibitor R115777 (Zarnestra) synergistically enhances growth inhibition and apoptosis induced on epidermoid cancer cells by Zoledronic acid (Zometa) and Pamidronate. Oncogene 23 6900-6913.

Caraglia M, Addeo R, Costanzo R, Montella L, Faiola V, Marra M, Abbruzzese A, Palmieri G, Budillon A, Grillone F, Venuta S, Tagliaferri P \& Prete SD 2005 Phase II study of temozolomide plus pegylated liposomal doxorubicin in the treatment of brain metastases from solid tumours. Cancer Chemotherapy and Pharmacology July 12 1-6 [Epub ahead of print].

Carmeliet P 2003 Angiogenesis in health and disease. Nature Medicine 9 653-660.

Carmeliet P \& Jain RK 2000 Angiogenesis in cancer and other diseases. Nature 407 249-257.

Cattel L, Ceruti M \& Dosio F 2004 From conventional to stealth liposomes: a new Frontier in Cancer chemotherapy. Journal of Chemotherapy 16 (Suppl) 94-97.

Chen T, Berenson J, Vescio R, Swift R, Glichick A, Goodin S, LoRusso P, Ma P, Ravera C, Deckert F, Schran H, Seaman J \& Skerjanec A 2002 Pharmacokinetics and pharmacodynamics of zoledronic acid in cancer patients with bone metastases. Journal of Clinical Pharmacology $\mathbf{4 2}$ 1228-1236.

Chou TC \& Talalay P 1984 Quantitative analysis of doseeffect relationships: the combined effects of multiple drugs or enzyme inhibitors. Advances in Enzyme Regulation 22 27-55.

Clarke S, Vogel JP, Deschenes RJ \& Stock J 1988 Posttranslational modification of the Ha-ras oncogene protein: evidence for a third class of protein carboxyl methyltransferases. PNAS 85, 4643-4647.

Coleman RE 1997 Skeletal complications of malignancy. Cancer 80 1588-1594.

Coleman RE 2001 Metastatic bone disease: clinical features, pathophysiology and treatment strategies. Cancer Treatment Review 27 165-176.

Coleman RE, Major P, Lipton A, Brown JE, Lee KA, Smith M, Saad F, Zheng M, Hei YJ, Seaman J \& Cook R 2005 Predictive value of bone resorption and formation markers in cancer patients with bone metastases receiving the bisphosphonate zoledronic acid. Journal of Clinical Oncology 23 4925-4935.

Conte PF, Latreille J, Mauriac L, Calabresi F, Santos R, Campos D, Bonneterre J, Francini G \& Ford JM 1996 Delay in progression of bone metastases in breast cancer patients treated with intravenous pamidronate: results from a multinational randomized controlled trial. The Aredia Multinational Cooperative Group. Journal of Clinical Oncology 14 2552-2559.

Cook RJ \& Lawless JF 1996 Interim monitoring of longitudinal comparative studies with recurrent event responses. Biometrics 52 1311-1323. 
Cooper CR, Chay CH \& Pienta KJ 2002 The role of $\alpha_{v} \beta_{3}$ in prostate cancer progression. Neoplasia 4 191-194.

Corey E, Brown LG, Quinn JE, Poot M, Roudier MP, Higano CS \& Vessella RL 2003 Zoledronic acid exhibits inhibitory effects on osteoblastic and osteolytic metastases of prostate cancer. Clinical Cancer Research 295 295-306.

Coxon FP, Helfrich MH, Larijani B, Muzylak M, Dunford JE, Marshall D, McKinnon AD, Nesbitt SA, Horton MA, Seabra MC, Ebetino FH \& Rogers MJ 2001 Identification of a novel phosphonocarboxylate inhibitor of Rab geranylgeranyl transferase that specifically prevents Rab prenylation in osteoclasts and macrophages. Journal of Biological Chemistry 276 48213-48222.

Coxon JP, Oades GM, Kirby RS \& Colston KW 2004 Zoledronic acid induces apoptosis and inhibits adhesion to mineralized matrix in prostate cancer cells via inhibition of protein prenylation. BJU International 94 164-170.

Croucher PI, De Hendrik R, Perry MJ, Hijzen A, Shipman CM, Lippitt J, Green J, Van Marck E, Van Camp B \& Vanderkerken K 2003 Zoledronic acid treatment of 5T2MM-bearing mice inhibits the development of myeloma bone disease: evidence for decreased osteolysis, tumor burden and angiogenesis, and increased survival. Journal of Bone and Mineral Research 18 482-492.

Danenberg HD, Golomb G, Groothuis A, Gao J, Epstein H, Swaminathan RV, Seifert P \& Edelman ER 2003 Liposomal alendronate inhibits systemic innate immunity and reduces in-stent neointimal hyperplasia in rabbits. Circulation 108 2798-2804.

Denoyelle C, Hong L, Vannier JP, Soria J \& Soria C 2003 New insights into the actions of bisphosphonate zoledronic acid in breast cancer cells by dual RhoAdependent and -independent effects. British Journal of Cancer 88 1631-1640.

Diel IJ, Solomayer EF, Costa SD, Gollan C, Goerner R, Wallwiener D, Kaufmann M \& Bastert G 1998 Reduction in new metastases in breast cancer with adjuvant clodronate treatment. New England Journal of Medicine 339 357-363.

Druker BJ, Sawyers CL, Kantarjian H, Resta DJ, Reese SF, Ford JM, Capdeville R \& Talpaz M 2001a Activity of a specific inhibitor of the BCR-ABL tyrosine kinase in the blast crisis of chronic myeloid leukaemia and acute lymphoblastic leukemia with the Philadelphia chromosome. New England Journal of Medicine $\mathbf{3 4 4}$ 1038-1042.

Druker BJ, Talpaz M, Resta DJ, Peng B, Buchdunger E, Ford JM, Lydon NB, Kantarjian H, Capdeville R, OhnoJones S et al. $2001 b$ Efficacy and safety of a specific inhibitor of the BCR-ABL tyrosine kinase in chronic myeloid leukemia. New England Journal of Medicine 344 1031-1037.

Dunford JE, Thompson K, Coxon FP, Luckman SP, Hahn FM, Poulter CD, Ebetino FH \& Rogers MJ 2001 Structure-activity relationships for inhibition of farnesyl diphosphate synthase in vitro and inhibition of bone resorption in vivo by nitrogen-containing bisphosphonates. Journal of Pharmacology and Experimental Therapeutics 296 235-242.

Ernst DS, Tannock IF, Winquist EW, Venner PM, Reyno L, Moore MJ, Chi K, Ding K, Elliott C \& Parulekar W 2003 Randomized, double-blind, controlled trial of mitoxantrone/prednisone and clodronate versus mitoxantrone/prednisone and placebo in patients with hormone-refractory prostate cancer and pain. Journal of Clinical Oncology 21 3335-3342.

Ferlay J, Bray F, Pisani P \& Parkin DM 2001 GLOBOCAN 2000. Cancer Incidence, Mortality and Prevalence Worldwide, CancerBase no. 5. Lyon: IARC Press.

Fleisch H 1998 Bisphosphonates: mechanisms of action. Endocrine Review 19 80-100.

Fleisch H 2002 Development of bisphosphonates. Breast Cancer Research 4 30-34.

Fournier P, Boissier S, Filleur S, Guglielmi J, Cabon F, Colombel M \& Clezardin P 2002 Bisphosphonates inhibit angiogenesis in vitro and testosterone-stimulated vascular regrowth in the ventral prostate in castrated rats. Cancer Research 62 6538-6544.

Fromigue O, Lagneaux L \& Body JJ 2000 Bisphosphonates induce breast cancer cell death in vitro. Journal of Bone and Mineral Research 15 2211-2221.

Fujita T, Izumo N, Fukuyama R, Meguro T, Yasutomi C, Nakamuta H \& Koida M 2001 Incadronate and etidronate accelerate phosphate-primed mineralization of MC4 cells via ERK1/2-Cbfal signaling pathway in a Ras-independent manner: further involvement of mevalonate-pathway blockade for incadronate. Japanese Journal of Pharmacology 86 86-96.

Fujita H, Utsumi T, Muranaka S, Ogino T, Yano H, Akiyama J, Yasuda T \& Utsumi K 2005 Involvement of Ras/extracellular signal-regulated kinase, but not Akt pathway in risedronate-induced apoptosis of U937 cells and its suppression by cytochalasin B. Biochemical Pharmacology 69 1773-1784.

Gabizon A, Shmeeda H \& Barenholz Y 2003 Pharmacokinetics of pegylated liposomal Doxorubicin: review of animal and human studies. Clinical Pharmacokinetics 42 419-436.

Ghosh D \& Lin DY 2000 Nonparametric analysis of recurrent events and death. Biometrics 56 554-562.

Gibbs JB 2001 Farnesyltransferase inhibitors. In The Enzymes, 3rd edn, vol XXI, pp. 81-103. Ed DS Sigman. San Diego: Academic Press.

Green JR 2003 Antitumor effects of bisphosphonates. Cancer $97840-847$.

Hancock JF, Cadwallader K \& Marshall CJ 1991 Methylation and proteolysis are essential for efficient membrane binding of prenylated p $21 \mathrm{~K}-\operatorname{ras}(\mathrm{B}) . E M B O$ Journal 10 641-646.

Harms JF \& Welch DR 2003 MDA-MB-435 human breast carcinoma metastasis to bone. Clinical and Experimental Metastasis 20 327-334. 
Harrington KJ, Syrigos KN \& Vile RG 2002 Liposomally targeted cytotoxic drugs for the treatment of cancer. Journal of Pharmacy and Pharmacology 54 1573-1600.

Hightower KE, Huang C, Casey PJ \& Fierke CA 1998 H-Ras peptide and protein substrates bind protein farnesyltransferase as an ionized thiolate. Biochemistry 37 15555-15562.

Hiraga T, Williams PJ, Mundy GR \& Yoneda T 2001 The bisphosphonate ibandronate promotes apoptosis in MDA-MB-231 human breast cancer cells in bone metastases. Cancer Research 61 4418-4424.

Hofmann WK, Jones LC, Lemp NA, de Vos S, Gschaidmeier H, Hoelzer D, Ottmann OG \& Koeffler HP 2002 Ph ${ }^{+}$ acute lymphoblastic leukemia resistant to the tyrosine kinase inhibitor STI571 has a unique BCRABL gene mutation. Blood 99 1860-1862.

Hoover RR, Mahon FX, Melo JV \& Daley GQ 2002 Overcoming STI571 resistance with the farnesyltransferase inhibitor SCH66336. Blood 100 1068-1071.

Hortobágyi GN, Theriault RL, Porter L, Blayney D, Lipton A, Sinoff C, Wheeler H, Simeone JF, Seaman J \& Knight RD 1996 Efficacy of pamidronate in reducing skeletal complications in patients with breast cancer and lytic bone metastases. Protocol 19 Aredia Breast Cancer Study Group. New England Journal of Medicine 335 1785-1791.

Hortobágyi GN, Theriault RL, Lipton A, Porter L, Blayney D, Sinoff C, Wheeler H, Simeone JF, Seaman JJ, Knight RD et al. 1998 Long-term prevention of skeletal complications of metastatic breast cancer with pamidronate. Protocol 19 Aredia Breast Cancer Study Group. Journal of Clinical Oncology 16 2038-2044.

Huang CC, Casey PJ \& Fierke CA 1997 Evidence for a catalytic role of zinc in protein farnesyltransferase. Spectroscopy of $\mathrm{Co}^{2+}$-farnesyltransferase indicates metal coordination of the substrate thiolate. Journal of Biological Chemistry 272 20-23.

Hughes DE, Wright KR, Uy HL, Sasaki A, Yoneda T, Roodman GD, Mundy GR \& Boyce BF 1995 Bisphosphonates promote apoptosis in murine osteoclasts in vitro and in vivo. Journal of Bone and Mineral Research 10 1478-1487.

Hultborn R, Gundersen S, Ryden S, Holmberg E, Carstensen J, Wallgren UB, Killany S, Andreassen L, Carlsson G, Fahl N et al. 1999 Efficacy of pamidronate in breast cancer with bone metastases: a randomized, double-blind placebo-controlled multicenter study. Anticancer Research 19 3383-3392.

Jagdev SP, Coleman RE, Shipman CM, Rostami HA \& Croucher PI 2001 The bisphosphonate, zoledronic acid, induces apoptosis of breast cancer cells: evidence for synergy with paclitaxel. British Journal of Cancer $\mathbf{8 4}$ 1126-1134.

Johnson JR, Williams G \& Pazdur R 2003 End points and United States Food and Drug Administration approval of oncology drugs. Journal of Clinical Oncology 21 1404-1411.
Kohno N, Aogi K, Minami H, Nakamura S, Asaga T, Iino Y, Watanabe T, Goessl C, Ohashi Y \& Takashima S 2004 A randomized, double-blind, placebo-controlled phase III trial of zoledronic acid in the prevention of skeletal complications in Japanese women with bone metastases from breast cancer. Proceedings of the American Society of Clinical Oncology, 40th Annual Meeting, New Orleans, LA, USA Poster Number 668.

Kohno N, Aogi K, Minami H, Nakamura S, Asaga T, Iino Y, Watanabe T, Goessl C, Ohashi Y \& Takashima S 2005 Zoledronic acid significantly reduces skeletal complications compared with placebo in Japanese women with bone metastases from breast cancer: a randomized, placebo-controlled trial. Journal of Clinical Oncology 23 3314-3321.

Kristensen B, Ejlertsen B, Groenvold M, Hein S, Loft H \& Mouridsen HT 1999 Oral clodronate in breast cancer patients with bone metastases: a randomized study. Journal of International Medicine 246 67-74.

Kuroda J, Kimura S, Segawa H, Sato K, Matsumoto S, Nogawa M, Yuasa T, Kobayashi Y, Yoshikawa T, Ottmann OG \& Maekawa T 2004 p53-independent antitumor effects of the nitrogen-containing bisphosphonate zoledronic acid. Cancer Science 95 186-192.

le Coutre P, Tassi E, Varella-Garcia M, Barni R, Mologni L, Cabrita G, Marchesi E, Supino R \& GambacortiPasserini C 2000 Induction of resistance to the Abelson inhibitor STI571 in human leukemic cells through gene amplification. Blood 95 1758-1766.

Lee MV, Fong EM, Singer FR \& Guenette RS 2001 Bisphosphonate treatment inhibits the growth of prostate cancer cells. Cancer Research 61 2602-2608.

Lerner EC, Qian Y, Blaskovich MA, Fossum RD, Vogt A, Sun J, Cox AD, Der CJ, Hamilton AD \& Sebti SM 1995 Ras CAAX peptidomimetic FTI-277 selectively blocks oncogenic Ras signaling by inducing cytoplasmic accumulation of inactive Ras-Raf complexes. Journal of Biological Chemistry 270 26802-26806.

Lerner EC, Zhang TT, Knowles DB, Qian Y, Hamilton AD \& Sebti SM 1997 Inhibition of the prenylation of K-Ras, but not $\mathrm{H}$ - or N-Ras, is highly resistant to CAAX peptidomimetics and requires both a farnesyltransferase and a geranylgeranyltransferase I inhibitor in human tumor cell lines. Oncogene 15 1283-1288.

Lin JH 1996 Bisphosphonates: a review of their pharmacokinetic properties. Bone 18 75-85.

Lipton A, Theriault RL, Hortobagyi GN, Simeone J, Knight RD, Mellars K, Reitsma DJ, Heffernan M \& Seaman JJ 2000 Pamidronate prevents skeletal complications and is effective palliative treatment in women with breast carcinoma and osteolytic bone metastases: long term follow-up of two randomized, placebo-controlled trials. Cancer 88 1082-1090.

Lipton A, Zheng M \& Seaman J 2003 Zoledronic acid delays the onset of skeletal-related events and progression of skeletal disease in patients with advanced renal cell carcinoma. Cancer 98 962-969. 
Lipton A, Seaman J \& Zheng M 2004 Long-term efficacy and safety of zoledronic acid in patients with bone metastases from renal cell carcinoma. What is new in bisphosphonates? In Seventh Workshop on Bisphosphonates - From the Laboratory to the Patient, Davos, Switzerland Poster Number 28.

Lowy DR \& Willumsen BM 1993 Function and regulation of ras. Annual Review of Biochemistry 62 851-891.

Luckman SP, Hughes DE, Coxon FP, Graham R, Russell G \& Rogers MJ 1998 Nitrogen-containing bisphosphonates inhibit the mevalonate pathway and prevent post-translational prenylation of GTP-binding proteins, including Ras. Journal of Bone And Mineral Research 13, 581-589.

Mahon FX, Deininger MW, Schultheis B, Chabrol J, Reiffers J, Goldman JM \& Melo JV 2000 Selection and characterization of BCR-ABL positive cell lines with differential sensitivity to the tyrosine kinase inhibitor STI571: diverse mechanisms of resistance. Blood 96 1070-1079.

Major PP \& Cook R 2002 Efficacy of bisphosphonates in the management of skeletal complications of bone metastases and selection of clinical endpoints. American Journal of Clinical Oncology 25 S10-S18.

Major PP, Cook RJ, Chen BL \& Zheng N 2003 Multiple event analysis of zoledronic acid trials in patients with cancer metastatic to bone. Proceedings of the American Association for Cancer Research 22762.

Major PP, Cook RJ, Chen BL \& Zheng N 2004 Survivaladjusted cumulative event analysis of skeletal-related events in patients with cancer metastatic to bone in trials of zoledronic acid. What is new in bisphosphonates? In Seventh Workshop on Bisphosphonates - From the Laboratory to the Patient, Davos, Switzerland.

Matsumoto S, Kimura S, Segawa H, Kuroda J, Yuasa T, Sato K, Nogawa M, Tanaka F, Maekawa T \& Wada H 2005 Efficacy of the third-generation bisphosphonate, zoledronic acid alone and combined with anti-cancer agents against small cell lung cancer cell lines. Lung Cancer 47 31-39.

Montague R, Hart CA, George NJ, Ramani VA, Brown MD \& Clarke NW 2004 Differential inhibition of invasion and proliferation by bisphosphonates: anti-metastatic potential of zoledronic acid in prostate cancer. European Urology 46 389-402.

Mundy GR, Yoneda T \& Hiraga T 2001 Preclinical studies with zoledronic acid and other bisphosphonates: impact on the bone microenvironment. Seminars in Oncology $\mathbf{2 8}$ 35-44.

Neville-Webbe HL, Holen I \& Coleman RE 2002 The antitumour activity of bisphosphonates. Cancer Treatment Reviews 28 305-319.

Nogawa M, Yuasa T, Kimura S, Kuroda J, Segawa H, Sato K, Yokota A, Koizumi M \& Maekawa T 2005 Zoledronic acid mediates Ras-independent growth inhibition of prostate cancer cells. Oncology Research 15 1-9.
Ottmann OG \& Hoelzer D 2002 The ABL tyrosine kinase inhibitor STI571 (Glivec) in Philadelphia positive acute lymphoblastic leukemia - promises, pitfalls and possibilities. Hematology Journal 3 2-6.

Paterson AH, Powles TJ, Kanis JA, McCloskey E, Hanson J \& Ashley S 1993. Double-blind controlled trial of oral clodronate in patients with bone metastases from breast cancer. Journal of Clinical Oncology 11 59-65.

Pécheur I, Peyruchaud O, Serre CM, Guglielmi J, Voland C, Bourre F, Margue C, Cohen-Solal M, Buffet A, Kieffer N \& Clezardin P 2002 Integrin $\alpha_{\mathrm{v}} \beta_{3}$ expression confers on tumor cells a greater propensity to metastasize to bone. FASEB Journal 16 1266-1268.

Powles TJ, McCloskey E, Paterson AH, Ashley S, Tidy VA, Nevantaus A, Rosenquist K \& Kanis J 1998 Oral clodronate and reduction in loss of bone mineral density in women with operable primary breast cancer. Journal of the National Cancer Institute 90 704-708.

Powles T, Paterson S, Kanis JA, McCloskey E, Ashley S, Tidy A, Rosenquist K, Smith I, Ottestad L, Legault S et al. 2002 Randomized, placebo-controlled trial of clodronate in patients with primary operable breast cancer. Journal of Clinical Oncology 20 3219-3224.

Reid TS, Terry KL, Casey PJ \& Beese LS 2004 Crystallographic analysis of CaaX prenyltransferases complexed with substrates defines rules of protein substrate selectivity. Journal of Molecular Biology 343 417-433.

Reszka AA, Halasy-Nagy JM, Masarachia PJ, Rodan GA 1999 Bisphosphonates act directly on the osteoclast to induce caspase cleavage of mst 1 kinase during apoptosis. A link between inhibition of the mevalonate pathway and regulation of an apoptosis-promoting kinase. Journal of Biological Chemistry 274 34967-34973.

Reszka AA, Halasy-Nagy J \& Rodan GA 2001 Nitrogenbisphosphonates block retinoblastoma phosphorylation and cell growth by inhibiting the cholesterol biosynthetic pathway in a keratinocyte model for esophageal irritation. Molecular Pharmacology 59 193-202.

Rodan GA 1998 Mechanisms of action of bisphosphonates. Annual Review of Pharmacology and Toxicology $\mathbf{3 8}$ 375-388.

Rogers MJ, Brown RJ, Hodkin V, Blackburn GM, Russell RG \& Watts DJ $1996 a$ Bisphosphonates are incorporated into adenine nucleotides by human aminoacyl-tRNA synthetase enzymes. Biochemical And Biophysical Research Communications 224 863-869.

Rogers MJ, Chilton KM, Coxon FP, Lawry J, Smith MO, Suri S \& Russell RG 1996 b Bisphosphonates induce apoptosis in mouse macrophage-like cells in vitro by a nitric oxide-independent mechanism. Journal of Bone and Mineral Research 11 1482-1491.

Rogers MJ, Gordon S, Benford HL, Coxon FP, Luckman SP, Monkkonen J \& Frith JC 2000 Cellular and molecular mechanisms of action of bisphosphonates. Cancer $\mathbf{8 8}$ 2961-2978. 
Rosen LS, Gordon D, Kaminski M, Howell A, Belch A, Mackey J, Apffelstaedt J, Hussein M, Coleman RE, Reitsma DJ et al. 2001 Zoledronic acid versus pamidronate in the treatment of skeletal metastases in patients with breast cancer or osteolytic lesions of multiple myeloma: a phase III, double-blind, comparative trial. Cancer Journal 7 377-387.

Rosen LS, Gordon D, Kaminski M, Howell A, Belch A, Mackey J, Apffelstaedt J, Hussein MA, Coleman RE, Reitsma DJ et al. 2003 Long-term efficacy and safety of zoledronic acid compared with pamidronate disodium in the treatment of skeletal complications in patients with advanced multiple myeloma or breast carcinoma: a randomized, double-blind, multicenter, comparative trial. Cancer 98 1735-1744.

Rosen LS, Gordon D, Tchekmedyian NS, Yanagihara R, Hirsh V, Krzakowski M, Pawlicki M, De Souza P, Zheng M, Urbanowitz G et al. $2004 a$ Long-term efficacy and safety of zoledronic acid in the treatment of skeletal metastases in patients with nonsmall cell lung carcinoma and other solid tumors: a randomized, phase III, doubleblind, placebo-controlled trial. Cancer 100 2613-2621.

Rosen LS, Gordon DH, Dugan W Jr, Major P, Eisenberg PD, Provencher L, Kaminski M, Simeone J, Seaman J, Chen BL et al. $2004 b$ Zoledronic acid is superior to pamidronate for the treatment of bone metastases in breast carcinoma patients with at least one osteolytic lesion. Cancer 100 36-43.

Roskoski R Jr 2003 Protein prenylation: a pivotal posttranslational process. Biochemical And Biophysical Research Communications 303 1-7.

Ross JR, Saunders Y, Edmonds PM, Patel S, Broadley KE \& Johnston SR 2003 Systematic review of role of bisphosphonates on skeletal morbidity in metastatic cancer. British Medical Journal 327 1-7.

Rowell CA, Kowalczyk JJ, Lewis MD \& Garcia AM 1997 Direct demonstration of geranylgeranylation and farnesylation of Ki-Ras in vivo. Journal of Biological Chemistry 272 14093-14097.

Saad F, Gleason DM, Murray R, Tchekmedyian S, Venner P, Lacombe L, Chin JL, Vinholes JJ, Goas JA, Zheng M et al. 2004 Long-term efficacy of zoledronic acid for the prevention of skeletal complications in patients with metastatic hormone-refractory prostate cancer. Journal of the National Cancer Institute 96 879-882.

Saarto T, Blomqvist C, Valimaki M, Makela P, Sarna S \& Elomaa I 1997 Clodronate improves bone mineral density in post-menopausal breast cancer patients treated with adjuvant antioestrogens. British Journal of Cancer $\mathbf{7 5}$ 602-605.

Santini D, Vincenzi B, Avvisati G, Dicuonzo G, Battistoni F, Gavasci M, Salerno A, Denaro V \& Tonini G 2002 Pamidronate induces modifications of circulating angiogenetic factors in cancer patients. Clinical Cancer Research 8 1080-1084.

Santini D, Vincenzi B, Dicuonzo G, Avvisati G, Massacesi C, Battistoni F, Gavasci M, Rocci L, Tirindelli MC,
Altomare V, Tocchini M, Bonsignori M \& Tonini G 2003 Zoledronic acid induces significant and long-lasting modifications of circulating angiogenic factors in cancer patients. Clinical Cancer Research 9 2893-2897.

Sawada K, Morishige K, Tahara M, Kawagishi R, Ikebuchi Y, Tasaka K \& Murata Y 2002 Alendronate inhibits lysophosphatidic acid-induced migration of human ovarian cancer cells by attenuating the activation of rho. Cancer Research 62 6015-6020.

Senaratne SG, Mansi JL \& Colston KW 2002 The bisphosphonate zoledronic acid impairs Ras membrane localisation and induces cytochrome $\mathrm{c}$ release in breast cancer cells. British Journal of Cancer $\mathbf{8 6}$ 1479-1486.

Shipman CM, Rogers MJ, Apperley JF, Russell RG \& Croucher PI 1997 British Journal of Haematology 98 665-672.

Skerjanec A, Berenson J, Hsu C, Major P, Miller WH Jr, Ravera C, Schran H, Seaman J, \& Waldmeier F 2003 The pharmacokinetics and pharmacodynamics of zoledronic acid in cancer patients with varying degrees of renal function. Journal of Clinical Pharmacology 43 154-162.

Soma MR, Corsini A \& Paoletti R 1992 Cholesterol and mevalonic acid modulation in cell metabolism and multiplication. Toxicology Letters 64-65 1-15.

Spence RA \& Casey PJ 2001 Mechanisms of catalysis by protein farnesyltransferase. In The Enzymes, 3rd edn, vol. XXI, pp. 1-18. Ed DS Sigman. San Diego: Academic Press.

Tassone P, Forciniti S, Galea E, Morrone G, Turco MC, Martinelli V, Tagliaferri P \& Venuta S 2000 Growth inhibition and synergistic induction of apoptosis by zoledronate and dexamethasone in human myeloma cell lines. Leukemia 14 841-844.

Tassone P, Tagliaferri P, Viscomi C, Palmieri C, Caraglia M, D'Alessandro A, Galea E, Goel A, Abbruzzese A, Boland CR \& Venuta S 2003 Zoledronic acid induces antiproliferative and apoptotic effects in human pancreatic cancer cells in vitro. British Journal of Cancer 88 1971-1978.

Terry KL, Long SB \& Beese LS 2001 Structure of protein farnesyltransferase. In The Enzymes, 3rd edn, vol. XXI, pp. 19-46. Ed DS Sigman. San Diego: Academic Press.

Theriault RL, Lipton A, Hortobagyi GN, Leff R, Gluck S, Stewart JF, Costello S, Kennedy I, Simeone J, Seaman JJ et al. 1999 Pamidronate reduces skeletal morbidity in women with advanced breast cancer and lytic bone lesions: a randomized, placebo-controlled trial. Protocol 18 Aredia Breast Cancer Study Group. Journal of Clinical Oncology 17 846-854.

Tubiana-Hulin M, Beuzeboc P, Mauriac L, Barbet N, Frenay M, Monnier A, Pion JM, Switsers O, Misset JL, Assadourian S et al. 2001 Double-blinded controlled study comparing clodronate versus placebo in patients with breast cancer bone metastases. Bulletin du Cancer $\mathbf{8 8}$ 701-707. 
Turhan AG, Solary E, Vainchenker W \& Dusanter-Fourt I 1998 Molecular pathophysiology of chronic myelogeneous leukemia. Hematology and Cell Therapy 40 217-221.

Twiss IM, Pas O, Ramp-Koopmanschap W, Den Hartigh J \& Vermeij P 1999 The effects of nitrogen-containing bisphosphonates on human epithelial (Caco-2) cells, an in vitro model for intestinal epithelium. Journal of Bone and Mineral Research 14 784-791.

Urano J, Yang W, Tamanoi F 2001 Mutational analysis of protein farnesyltransferase. In The Enzymes, 3rd edn, vol. XXI, pp. 47-80. Ed DS Sigman. San Diego: Academic Press.

van Beek E, Pieterman E, Cohen L, Lowik C \& Papapoulos S $1999 a$ Nitrogen-containing bisphosphonates inhibit isopentenyl pyrophosphate isomerase/farnesyl pyrophosphate synthase activity with relative potencies corresponding to their antiresorptive potencies in vitro and in vivo. Biochemical and Biophysical Research Communications 255 491-494.

van Beek E, Pieterman E, Cohen L, Lowik C \& Papapoulos S $1999 b$ Farnesyl pyrophosphate synthase is the molecular target of nitrogen-containing bisphosphonates.

Biochemical and Biophysical Research Communications 264 108-111.

van Beek ER, Cohen LH, Leroy IM, Ebetino FH, Lowik CW \& Papapoulos SE 2003 Differentiating the mechanisms of antiresorptive action of nitrogen containing bisphosphonates. Bone 33 805-811.

van der Pluijm G, Vloedgraven $H$, van Beek E, van der Wee-Pals L, Lowik C \& Papapoulos S 1996 Bisphosphonates inhibit the adhesion of breast cancer cells to bone matrices in vitro. Journal of Clinical Investigation 98 698-705.

van Rooijen N \& van Kesteren-Hendrikx E 2002 Clodronate liposomes: perspectives in research and therapeutics. Journal of Liposome Research 12 81-94.

Virtanen SS, Vaananen HK, Harkonen PL \& Lakkakorpi PT 2002 Alendronate inhibits invasion of PC-3 prostate cancer cells by affecting the mevalonate pathway. Cancer Research 62 2708-2714.

Vogt HC, Kolotas C, Martin T, Schneider LV, GoesSchmieder R, Mitrou PS, Diergarten K, Kober B \& Zambouglou N 1996 Paclitaxel and simultaneous radiation in locally advanced stage IIIA/B non-small cell lung cancer: a clinical phase I study. Seminrs in Oncology 23 120-123.

Weisberg E \& Griffin JD 2000 Mechanism of resistance to the ABL tyrosine kinase inhibitor STI571 in BCR/ ABL-transformed hematopoietic cell lines. Blood $\mathbf{9 5}$ 3498-3505.
Whyte DB, Kirschmeier P, Hockenberry TN, Nunez-Oliva I, James L, Catino JJ, Bishop WR \& Pai JK 1997 K- and NRas are geranylgeranylated in cells treated with farnesyl protein transferase inhibitors. Journal of Biological Chemistry 272 14459-14464.

Williams G, Pazdur R \& Temple R 2004 Assessing tumorrelated signs and symptoms to support cancer drug approval. Journal of Biopharmacology Statistics 14 5-21.

Witters LM, Crispino J, Fraterrigo T, Green J \& Lipton A 2003 Effect of the combination of docetaxel, zoledronic acid, and a COX-2 inhibitor on the growth of human breast cancer cell lines. American Journal Clinical Oncology 26 S92-S97.

Wood J, Bonjean K, Ruetz S, Bellahcene A, Devy L, Foidart JM, Castronovo V \& Green JR 2002 Novel antiangiogenic effects of the bisphosphonate compound zoledronic acid. Journal of Pharmacology and Experimental Therapeutics 302 1055-1061.

Yata K, Otsuki T, Yamada O, Wada H, Yawata Y \& Sugihara T 2002 Synergistic growth inhibition of YM529 with biologic response modifiers (BRMs) in myeloma cells. International Journal of Hematology 75 534-539.

Yokayama K \& Gelb MH 2001 Protein geranylgeranyltransferase type I. In The Enzymes, 3rd edn, vol. XXI, pp. 105-130. Ed DS Sigman. San Diego: Academic Press.

Yu C, Krystal G, Varticovksi L, McKinstry R, Rahmani M, Dent P \& Grant S 2002 Pharmacologic mitogen-activated protein/extracellular signal-regulated kinase kinase/ mitogen-activated protein kinase inhibitors interact synergistically with STI571 to induce apoptosis in Bcr/ Abl-expressing human leukemia cells. Cancer Research 62 188-199.

Yuasa T, Nogawa M, Kimura S, Yokota A, Sato K, Segawa H, Kuroda J \& Maekawa T 2005 A third-generation bisphosphonate, minodronic acid (YM529), augments the interferon alpha/beta-mediated inhibition of renal cell cancer cell growth both in vitro and in vivo. Clinical Cancer Research 15 853-859.

Zekri J, Ahmed N, Coleman RE \& Hancock BW 2001

The skeletal metastatic complications of renal cell carcinoma. International Journal of Oncology 19 379-382.

Zhang FL \& Casey PJ 1996 Protein prenylation: molecular mechanisms and functional consequences. Annual Review of Biochemistry 65 241-269.

Zhang PL, Lun M, Siegelmann-Danieli N, Blasick TM \& Brown RE 2004 Pamidronate resistance and associated low ras levels in breast cancer cells: a role for combinatorial therapy. Annals of Clinical and Laboratory Science 34 263-270. 